\title{
Kentron
}

\section{Pisistrate au Lycée ou le temps de Cronos retrouvé}

\section{Francis Larran}

\section{OpenEdition}

\section{Journals}

Édition électronique

URL : http://journals.openedition.org/kentron/1108

DOI : 10.4000/kentron. 1108

ISSN : 2264-1459

\section{Éditeur}

Presses universitaires de Caen

\section{Édition imprimée}

Date de publication : 31 décembre 2012

Pagination : 53-88

ISBN : 978-2-84133-427-8

ISSN : 0765-0590

\section{Référence électronique}

Francis Larran, "Pisistrate au Lycée ou le temps de Cronos retrouvé », Kentron [En ligne], 28 | 2012, mis en ligne le 12 décembre 2017, consulté le 17 novembre 2020. URL : http://

journals.openedition.org/kentron/1108; DOI : https://doi.org/10.4000/kentron.1108

\section{(ब) $(\Theta \Theta$}

Kentron is licensed under a Creative Commons Attribution-NonCommercial-NoDerivatives 3.0 International License. 


\section{PISISTRATE AU LYCÉE OU LE TEMPS DE CRONOS RETROUVÉ}

Pour O. Murray, l'analyse de la tyrannie livrée par Aristote dans la Politique et nourrie par les informations collectées lors de la rédaction des 158 politeiai grecques menée par le Lycée reste «la plus fondée historiquement ${ }^{1}$ parmi toutes celles proposées par les penseurs du $\mathrm{IV}^{\mathrm{e}}$ siècle. La remarque a de quoi surprendre, car Aristote peut lui aussi se livrer à des jugements anachroniques ou à des analyses partisanes. Il envisage même de prêter foi à l'opinion commune :

Il faut aussi se servir des maximes qui sont dans toutes les bouches et employées par le commun des hommes, si elles sont utilisables; parce qu'elles sont communes, on les croit fondées sur le consentement unanime et d'une parfaite justesse; [...]

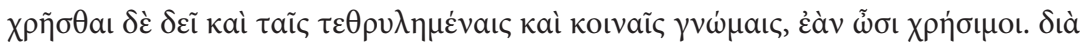

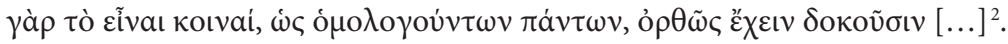

Comme exemple susceptible de contrarier la formule d'O. Murray, on compte, dans le corpus aristotélicien, l'élogieux portrait de Pisistrate, un tyran sous lequel les Athéniens auraient, disait-on, vécu comme à l'âge d'or ${ }^{3}$, car, en leur faisant retrouver la paix et la tranquillité, il mit fin à la stasis qui déchirait la cité après le départ de Solon ${ }^{4}$. La Constitution d'Athènes rappelle ainsi :

Il ne gênait la foule en rien pendant sa domination, mais il préparait toujours la paix et maintenait la tranquillité. C'est pourquoi [lacune : on répétait souvent?] que la tyrannie de Pisistrate était la vie du temps de Cronos.

1. Cf. Murray 1995, 148.

2. Aristote, Rhétorique, II, 21, 1395 a (traduction Dufour 1938, 109).

3. Depuis Hésiode, l'âge de Cronos fait figure d'âge d'or dans la littérature grecque. Les Travaux et les Jours, 109-125 et 134-135, rappellent ainsi que les hommes vivant au temps de Cronos appartiennent à la race d'or et que, tels des dieux, ils mènent une existence tranquille à l'abri des maux, de la misère, de la vieillesse et, à la différence des hommes de la race d'argent, de la démesure. Sur l'âge d'or et son utilisation littéraire, cf. Baldry 1952.

4. Aristote, Constitution d'Athènes, XIII, 1-2. Sur la solidité du régime de Pisistrate, son acceptation par les Athéniens et l'apaisement des tensions politiques, voir Sancisi-Weerdenburg 2000, 1-15 (notamment 8 sq.). 


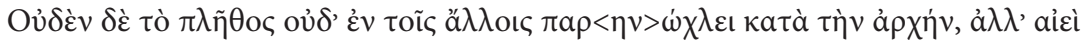

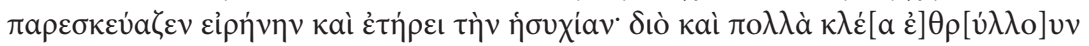

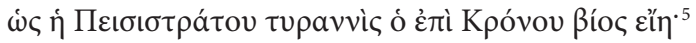

Plutôt que de prêter à Aristote des analyses susceptibles de répondre à nos canons contemporains de l'analyse historique ${ }^{6}$, la démarche la plus prudente reste de suivre l'appel à la vigilance lancé par N. Loraux ${ }^{7}$ et de considérer les sources littéraires anciennes dans leur singularité historique. Contre la tentation de voir dans la Constitution d'Athènes une archive taillée sur mesure pour les historiens d'aujourd'hui, il s'agira de replacer la formule «la tyrannie de Pisistrate était la vie du temps de Cronos» dans son contexte intellectuel de production pour en cerner l'origine et le sens ${ }^{8}$. On pourra ainsi comprendre dans quelle mesure la reprise de cette formule par Aristote ${ }^{9}$ est liée aux conceptions historiographiques du $\mathrm{IV}^{\mathrm{e}}$ siècle et à leurs enjeux mémoriels, combien elle dépend de la volonté du Stagirite de répondre aux polémiques du temps sur les traits à donner à la figure du monarque idéal. Cette formulation, enfin, nous invite à questionner les débats politiques qui agitent Athènes à l'heure de sa mise sous tutelle macédonienne.

La richesse du portrait de Pisistrate dans la Constitution d'Athènes n'est pas toujours là où l'on croit la trouver : plus qu'une simple compilation de données historiques passées au crible de la lucidité aristotélicienne, la figure du tyran athénien est surtout une pièce à replacer dans le puzzle des débats intellectuels des années $330-320^{10}$.

5. Aristote, Constitution d'Athènes, XVI, 7 (traduction Sève 2006, 84).

6. Sur le débat autour des qualités d'historien prêtées à Aristote, voir Gregorio 2001, notamment 71.

7. Selon N. Loraux, «Thucydide n'est pas un collègue», Quaderni di storia, 12, 1980, p. 55-81 (notamment p. 55, 56 et 70), l'historien ne doit pas s'incliner dans une crainte révérencielle devant les sources littéraires anciennes, dont la qualité est telle que bien souvent elles sont considérées comme "un monument, à jamais élevé dans le jardin des humanités, soustrait à la corrosion du temps comme à la relativité des lectures, et auquel on a rapport sous le signe de l'admiration : on en exalte la beauté [...], on en proclame l'inaltérable actualité, celle même des chefs-d'œuvre qui savent dire ce que l'homme a d'humain". Un travail de contextualisation historique est dès lors nécessaire pour les transformer en documents d'étude.

8. À la différence de Zatta 2010, qui montre, à partir d'Aristote, Constitution d'Athènes, XVI, 7, comment Pisistrate a pu utiliser le mythe de l'âge de Cronos pour asseoir son autorité et faire accepter son programme politique aux Athéniens du VI siècle, nous préférons éviter tout risque de surinterprétation anachronique en retenant uniquement la lettre du texte d'Aristote et en proposant de comprendre le on-dit à la lumière des sources du IV $\mathrm{I}^{\mathrm{e}}$ siècle qui le mentionnent pour la première fois.

9. Sans prétendre donner une solution à l'épineuse question de l'identité de l'auteur de la Constitution d'Athènes, nous proposons, par commodité, de l'attribuer à Aristote, tout en étant conscient que le Stagirite a présidé un travail d'équipe lors de la rédaction des 158 politeiai.

10. Pour la datation de la Constitution d'Athènes, nous privilégions l'hypothèse d'une période de rédaction assez longue (335-322). 


\section{Pisistrate au temps de Cronos, une tradition venue de l'historiographie classique?}

Quel chemin explorer pour espérer remonter aux origines de la tradition assurant, dans la Constitution d'Athènes, que «la tyrannie de Pisistrate était la vie du temps de Cronos » ? Faut-il d'abord interroger les textes historiques de la seconde moitié $\mathrm{du} \mathrm{V}^{\mathrm{e}}$ siècle qui, les premiers, transmettent la légende dorée du tyran athénien ${ }^{11}$ ? Élogieux, le portrait aristotélicien de Pisistrate fait écho aux informations recueillies par Hérodote comme par Thucydide ${ }^{12}$. À chaque fois, il s'agit de vanter le gouvernement de Pisistrate pour sa capacité à respecter les lois de Solon. À l'instar d'Hérodote ${ }^{13}$, qui affirme que

Dès lors [Pisistrate] fut maître d'Athènes, mais sans rien changer dans les magistratures existantes et sans toucher aux lois; il s'appuya sur les institutions en vigueur et son administration fut sage et bonne.

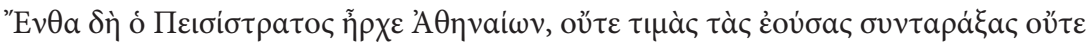

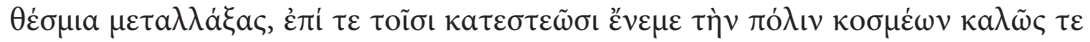

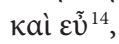

Aristote rappelle que

11. Sur la tradition légendaire entourant la figure de Pisistrate depuis la fin de l'époque archaïque jusqu'à Plutarque, cf. M. V. Skrzinskaja, «The Oral Tradition about Pisistratus », VDI, 110, 1969, p. 83-96, qui dégage trois phases dans l'histoire de la tradition de Pisistrate (la première phase, orale et favorable à Pisistrate, serait née du vivant du tyran; la deuxième, défavorable à Pisistrate, aurait duré de la chute de la tyrannie jusqu'au milieu du $\mathrm{V}^{\mathrm{e}}$ siècle; la dernière, littéraire, se baserait sur des récits à l'authenticité douteuse); Calabro 1984 estime, quant à elle, que la tradition d'anecdotes sur Pisistrate choisit, d'Hérodote à Plutarque, de le présenter comme un partisan de la véritable démocratie.

12. Pour Day \& Chambers 1962, 175, l'examen du chapitre XVI de la Constitution d'Athènes montre qu'Aristote ne sait rien de l'administration de Pisistrate, à l'exception de ce que Hérodote et Thucydide peuvent lui en apprendre. Voir aussi Pesely 1995.

13. Hérodote compte parmi les penseurs les plus estimés par Aristote. Considéré comme le type même de l'historikos par Aristote, Poétique, 9, 1451 b 1-4, seul historien cité dans la Constitution d'Athènes $(\mathrm{XIV}, 4)$, il est utilisé comme source aussi bien des œuvres de sciences naturelles que des travaux de sciences humaines (cf. Weil 1960, 316). Le parcours de Pisistrate dans la Constitution d'Athènes s'inspire souvent d'Hérodote (pour l'automutilation, la ruse du char, la coalition des factions de Mégaclès et de Lycurgue, la durée du second exil, le durcissement du régime sous les Pisistratides, confronter respectivement Constitution d'Athènes, XIV, 1; 4; 3 XV, 1-2; XVI, 7, et Hérodote, I, 59, 19-24; I, 60, 9-29; I, 60, 1; I, 52, 1-2; V, 55, 5-7).

14. Hérodote, I, 59 (traduction Barguet 1964, 73). Pour une mise en perspective critique des relations entretenues par Pisistrate avec les institutions athéniennes existantes au VI siècle, voir SancisiWeerdenburg 2000, 7-9. 
[...] le plus important de tout ce qu'on a dit est qu'il était d'un caractère affable et bienveillant. Car en tout domaine il voulait tout administrer conformément aux lois, sans s'attribuer aucun avantage.

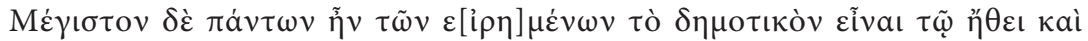

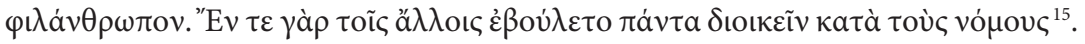

Bien qu'il ait une mauvaise image de la tyrannie ${ }^{16}$, Thucydide estime également que, sous le régime de Pisistrate et de ses fils, la cité gardait les lois anciennes ([...]

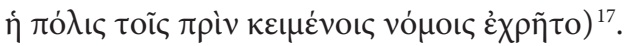

La tradition positive du tyran athénien est ainsi prolongée par Aristote. Il manque cependant l'essentiel. Ni Hérodote ni Thucydide n'évoquent la tradition assurant que «la tyrannie de Pisistrate était la vie du temps de Cronos», n'affublent Pisistrate de l'adjectif "proche du peuple» (dèmotikos) ${ }^{18}$ ou ne disent encore de lui que

[il] administrait avec modération les affaires de la cité, en citoyen plutôt qu'en tyran. Il était en général bienveillant et doux, et enclin au pardon envers les fautifs; et en particulier, il avançait de l'argent aux indigents pour leurs activités, en sorte qu'ils tirent leur subsistance de l'agriculture.

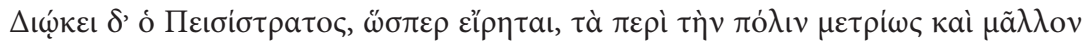

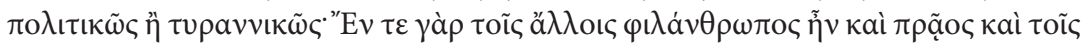

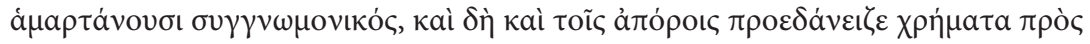

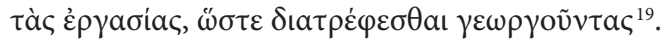

Dans la quête des origines de la tradition mentionnée au chapitre XVI de la Constitution d'Athènes et de la survalorisation légendaire de Pisistrate chez Aristote, il semble nécessaire d'abandonner la piste de la tradition historique née au Ve siècle pour privilégier celle de la pensée historiographique du IV $\mathrm{IV}^{\mathrm{e}}$ siècle.

Tels Éphore ${ }^{20}$ et Timée, Aristote cherche-t-il à compiler, dans la Constitution d'Athènes, toutes les informations accessibles ${ }^{21}$, à bâtir une œuvre à partir d'autres

15. Aristote, Constitution d'Athènes, XVI, 8 (traduction Sève 2006, 85).

16. Cf. Thucydide, I, 17.

17. Cf. Thucydide, VI, 54, 6.

18. Cf. Aristote, Constitution d'Athènes, XIII, 4.

19. Aristote, Constitution d'Athènes, XVI, 2 (traduction Sève 2006, 83 sq.).

20. L'influence d'Éphore sur Aristote est probable. Ses analyses sur la tyrannie de Pisistrate (Éphore FGH $70 \mathrm{~F}$ 181) pourraient notamment inspirer Aristote, Constitution d'Athènes, XVI, 6 (sur ce point, voir Rhodes 1981, 191 et 216).

21. Sur le travail de compilation d'Éphore et son goût du savoir encyclopédique, voir Van Effenterre 1967,33-35, et Momigliano 1983, 28. Sur la collecte systématique des informations par Aristote dans la littérature qui le précède, voir I. Düring, «Notes on the History of the Transmission of Aristotle's Writings », Göteborgs Högskolas Ársskrift, 56, 1950, p. 35-70, notamment 57 sq. 
œuvres et ainsi à enrichir le savoir historique? Aux élèves du Stagirite de consulter, dans cette perspective, les différents écrits qui évoquent la tyrannie de Pisistrate, qu'ils soient l'œuvre d'historiens ou bien encore d'académiciens qui, soucieux d'essayer leurs talents, produisent des dialogues poursuivant l'entreprise philosophique de leur maître Platon. Le dialogue du Pseudo-Platon, Hipparque ou l'homme cupide, pourrait ainsi être à l'origine ${ }^{22}$ de la tradition sur Pisistrate, puisqu'il associe en 229 b 3-7, pour la première fois dans la littérature grecque ancienne, le tyran à l'âge de Cronos. En faisant sienne une tradition utilisée par le Pseudo-Platon pour présenter, dans une perspective oligarchique, Hipparque comme le modèle du chef d'État, Aristote cherche peut-être à compléter les informations recueillies par Hérodote et Thucydide.

Par la reprise d'une formule laudative ignorée ou délaissée par les historiens $\mathrm{du} \mathrm{V}^{\mathrm{e}}$ siècle, le portrait aristotélicien de Pisistrate s'inscrit-il dans la tradition du portrait moral et de l'éloge individuel lancée par Xénophon et Isocrate ${ }^{23}$ ? Fascinés par l'affirmation d'individus exceptionnels ${ }^{24}$, appelés à jouer, depuis la Guerre du Péloponnèse et avec la montée en puissance de la monarchie macédonienne, un rôle providentiel sur la scène internationale, les hommes de lettres du IV siècle retiennent les vertus comme des armes décisives et célèbrent volontiers les hommes prompts à les utiliser pour guider le cours de l'histoire. Dans la galerie des éloges et des portraits moraux nés sous la plume de Xénophon ${ }^{25}$, d'Isocrate ${ }^{26}$, de Théopompe de $\operatorname{Chios}^{27}$ et des historiens d'Alexandre, le portrait du Pisistrate de la Constitution $d^{\prime}$ Athènes pourrait s'inscrire dans cette nouvelle orientation historiographique ${ }^{28}$.

22. Nous nous rangeons ici à l'avis de J. Souilhé, selon lequel le dialogue Hipparque ou l'homme cupide a été composé durant la première moitié du IV siècle. Pour les débats historiographiques sur la datation du dialogue, voir Platon, Euvres complètes. Tome XIII. Deuxième partie, Dialogues suspects, J. Souilhé (éd., trad.), Paris, Les Belles Lettres (CUF; 57), 1930 (rééd. 1981), p. 54-58.

23. L'influence d'Isocrate sur Aristote est d'autant plus probable que le Stagirite est passé par son école en 367 avant de se diriger vers l'Académie de Platon (cf. Louis 1990, 25).

24. Xénophon, Helléniques, V, 1, 4, considère ainsi que l'étude des personnalités marquantes est «l'occupation la plus digne d'un homme».

25. Xénophon est notamment l'auteur d'une histoire idéalisée de la jeunesse de Cyrus le Grand (Cyropédie) et de l'éloge du roi spartiate Agésilas.

26. On retiendra par exemple les éloges des rois Agamemnon et Évagoras (Panathénaïque [XII], 72-88, et Évagoras [IX]).

27. Sur le rôle historique majeur accordé à Philippe de Macédoine dans Les Philippiques de Théopompe, voir Duff 2003, 46 sq.

28. D’une façon plus générale, on notera qu'Aristote s'intéresse aussi, dans la Constitution d'Athènes, au caractère d'autres grandes figures politiques athéniennes (Solon, Thémistocle, Aristide, Cimon, Éphialte, Périclès) et qu'il structure l'Éthique à Nicomaque autour d'une galerie de portraits moraux (cf. Aubenque, 1963, 37). 
Éphore, Timée, Xénophon, Isocrate, Théopompe..., la liste est longue mais incomplète, car, parmi les inspirateurs probables du portrait aristotélicien de Pisistrate, il faut encore compter sur les Atthidographes. Outre quelques anecdotes ${ }^{29}$ et informations chronologiques précises ${ }^{30}$ qu'il puise dans les Atthis, Aristote s'engage, comme eux, dans une interprétation partisane et nostalgique du passé athénien ${ }^{31}$. Dans un siècle qui propose, depuis la Guerre du Péloponnèse, non plus une lecture commune de l'histoire athénienne, mais des interprétations plurielles et antagonistes du passé ${ }^{32}$, la figure de Pisistrate se pare, avec la tradition relative à l'âge de Cronos, d'une dimension mémorielle utile à Aristote pour faire valoir, dans l'agôn des conceptions historiographiques, sa conception d'une identité athénienne respectueuse de l'héritage législatif solonien.

La tentation est donc grande de voir dans les Atthis la source de la tradition associant Pisistrate à l'âge de Cronos, même si les preuves concrètes manquent tant les textes des Atthidographes sont conservés à l'état fragmentaire. Effectivement, les similitudes entre leurs travaux et la Constitution d'Athènes se donnent, nombreuses, à lire jusque dans le portrait de Pisistrate. Comme les Atthis ${ }^{33}$, Aristote voit dans le régime pisistratique une étape mémorable dans l'histoire linéaire et continue de la cité athénienne. À l'image des Atthidographes ${ }^{34}$, il utilise avec minutie des listes d'archontes ${ }^{35}$ comme trame chronologique pour traquer les anachronismes

29. Selon Rhodes 1981, 189, l'anecdote sur la réaction de Solon face à la demande de Pisistrate d'obtenir une garde (cf. Aristote, Constitution d'Athènes, XIV, 2 sq.) serait tirée des Atthis.

30. Voir ici Jacoby 1949, 185 sq., et Day \& Chambers 1962, 175.

31. Hartog 2005, 69, remarque à ce sujet : les cités du IV siècle « sont soucieuses de fixer publiquement par écrit leur "généalogie" politique et de rendre ainsi manifestes l'ancienneté et la continuité de leur histoire. Présence du passé et massif appel à lui, instrumentalisation de ce passé par les orateurs, tel est le climat dans lequel les études sur le passé [... et les histoires locales vont prendre un grand essor. Participant de ce contexte, elles sont aussi une façon de répondre aux doutes du temps, en fournissant des rappels et des repères, à un moment où les destructions, les épreuves et les morts dues à la guerre du Péloponnèse devaient renforcer l'impression de rupture avec une époque désormais révolue. [...]».

32. Voir ici Petre 2000.

33. Sur la conception linéaire de l'histoire dans les Atthis, voir Hartog 1997, 133 notamment; Hartog 2005, 85 sq., et Darbo-Peschanski 2001, 17 en particulier.

34. Sur les Atthis comme chroniques articulées autour des règnes de rois et des magistratures officielles, voir Harding 2008, 2.

35. Symptomatique de l'intérêt que portent au passé des cités qui entreprennent au IV ${ }^{\mathrm{e}}$ siècle de publier sur leurs murs des listes de magistrats afin de montrer la continuité et l'ancienneté de leur histoire (cf. Hartog, 2005, 83 sq.), le goût d'Aristote pour les chronologies officielles se retrouve encore dans son élaboration de la liste des vainqueurs des Jeux Pythiques (cf. Jaeger, 1997, 330 ; 338, et Louis 1990, 68) et confirme une fois de plus la proximité de son travail avec l'œuvre d'un Atthidographe, Hellanikos de Lesbos, qui, intéressé par les histoires régionales, a lui aussi publié des listes chronologiques de prêtresses d'Héra à Argos et de vainqueurs aux Karnea (cf. Harding 2008, 6). 
de ses prédécesseurs ${ }^{36}$. Comme les Atthidographes enfin, Aristote met à profit des sources de tout type ${ }^{37}$ pour cerner au plus près la mémoire collective athénienne de la tyrannie de Pisistrate et de ses fils : des sources matérielles ${ }^{38}$, des chansons de table ${ }^{39}$ et des traditions orales ${ }^{40}$. Elles permettent à Aristote d'expliquer certains aspects du présent athénien ${ }^{41}$ et de détailler la carte de ses lieux de mémoire :

C'est au cours d'une de ces sorties, dit-on, qu'arriva à Pisistrate l'anecdote de l'homme qui cultivait sur l'Hymette le champ appelé plus tard le «champ non imposable». Avisant donc quelqu'un qui piochait et travaillait une terre qui n'était que pierres, par étonnement, il chargea son esclave de demander ce qui poussait dans le champ : «Rien que des maux et des douleurs", dit l'autre, "et il faut que Pisistrate prenne la dîme de ces maux et de ces douleurs ». L'homme avait répondu sans le connaître, et Pisistrate, ravi de sa franchise et de son ardeur au travail, l'exempta de tout impôt.

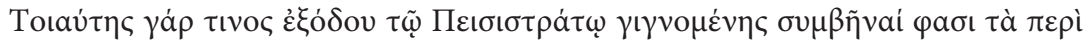

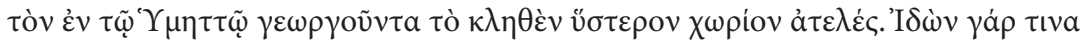

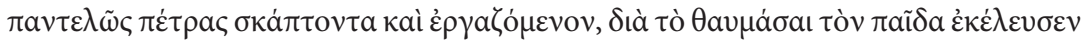

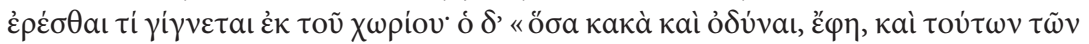

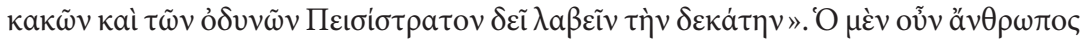

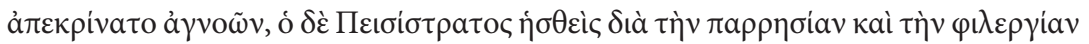

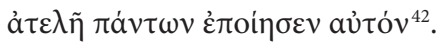

À l'instar de la tradition associant Pisistrate à l'âge d'or, l'anecdote sert sans doute l'identité d'une cité qui cherche, déstabilisée par la défaite de Chéronée (338), à se rassurer par une relecture patriotique des vestiges d'un passé grandiose ${ }^{43}$.

36. Par exemple, Aristote, Constitution d'Athènes, XVII, 1-2, considère comme anachronique la tradition suivant laquelle Pïsistrate a été aimé par Solon. Sur l'attention de la Constitution d'Athènes aux détails chronologiques, consulter Pearson, 1942, 102 sq.

37. Sur la diversité des sources exploitées par les Atthis, cf. Harding 2008, 3 sq.

38. Aristote, Constitution d'Athènes, XIII, 5 , exploite ainsi des listes de citoyens révisées après l'expulsion des Pisistratides pour comprendre la composition sociale de la faction des Diacriens menée par Pisistrate.

39. Aristote, Constitution d'Athènes, XIX, 3, et XX, 5, utilise ainsi d'anciennes chansons de table pour étayer ses analyses sur la résistance alcméonide aux Pisistratides.

40. Cf. Aristote, Constitution d'Athènes, XVI, $8:$ :Ce qu'on citait le plus, c'était son amour du peuple et son humanité». Sur l'habitude de Phanodèmos, de Démon comme d'Éphore d'exploiter ce type de parole populaire, voir Rhodes 1990, 78 sq. notamment, et Pearson 1942, 96.

41. Il partage ce souci avec les Atthidographes : cf. Harding 2008, 3.

42. Aristote, Constitution d'Athènes, XVI, 6 (traduction Sève 2006, 84). Voir encore la tradition légendaire de la réaction de Solon face à la demande d'une garde par Pisistrate (legetai) (Aristote, Constitution d'Athènes, XIV, 2).

43. Comme le rappellent Lycurgue, Contre Léocrate, 95 sq., et son anecdote sur l'origine du nom du Champ de la Piété en Sicile, les Athéniens, comme la plupart des Grecs du dernier tiers du IV siècle, 
La conclusion semble s'imposer d'elle-même : à l'instar des analyses des Atthidographes ou bien encore des remarques du Pseudo-Platon, la représentation aristotélicienne du tyran Pisistrate pourrait s'inscrire dans une voie politique partisane. Les similitudes sont nombreuses entre les Atthis et la Constitution d'Athènes, les partis pris d'Aristote apparents. Sans doute, mais le détail du texte se montre rétif. À l'image des autres développements de la Constitution d'Athènes, les chapitres consacrés à Pisistrate pourraient se distinguer par leur manque de cohérence politique. Si la tradition conservatrice domine, elle cohabite souvent avec des analyses de tendance démocratique défavorables au tyran athénien. Comment, par exemple, expliquer qu'Aristote puisse tout à la fois louer, grâce à des traditions orales, Pisistrate pour son humanité à l'égard du peuple athénien et considérer qu'il lui impose une taxe, la dîme, plus lourde que celle mentionnée par Thucydide ${ }^{44}$ ?

Déroutants, les paradoxes du texte n'ont de cesse d'alimenter les débats historiographiques sur le positionnement politique de la Constitution d'Athènes. On a tout essayé : un traité aristocratique ou oligarchique, un manifeste en faveur des idées modérément conservatrices d'Isocrate ou d'Androtion, un ouvrage conduit par les idées politiques de l'école platonicienne, une œuvre démocratique inspirée par la réaction patriotique qui suit l'affaire d'Harpale ${ }^{45} \ldots$ Le foisonnement d'hypothèses trahit à lui seul nos difficultés à appréhender le sens de la démarche d'Aristote : la présence de traditions politiques antagonistes dans son œuvre signe-t-elle son incapacité à porter un regard critique sur les sources consultées? Traduit-elle, au

goûtent les relectures patriotiques de leur paysage quotidien, car elles sont à même de rappeler la grandeur et l'ancienneté de leur cité.

44. Alors que Thucydide, VI, 54, 5, estime que Pisistrate exigeait des Athéniens le vingtième de leurs revenus, Aristote, Constitution d'Athènes, XVI, 4, considère qu'il "prélève une dîme des produits ". Pour Aristote, les tyrans ont pour habitude d'appauvrir leurs sujets au moyen de taxes et de prélèvements afin d'entretenir leur garde et d'empêcher leurs sujets, absorbés par leur travail, de conspirer (Aristote, Politique, V, 11, 1313 b 18-28). Il en va ainsi des Pisistratides, mais aussi de Denys de Syracuse et de Cypsélos de Corinthe, lequel leva lui aussi une dîme sur ses sujets (cf. Aristote, Économique, II, 1 et 20 b). Sur les taxes de Pisistrate et l'épineuse question de leur prélèvement, voir Mathieu 1915, 41 sq. et Sancisi-Weerdenburg, «Solon's hektemoroi and Pisistratid dekatemoroi», in De agricultura : in memoriam Pieter Willem De Neeve (1945-199o), H. Sancisi-Weerdenburg, R. J. van der Spek, H. C. Teitler et H. T. Wallinga (éd.), Amsterdam, J. C. Gieben (Dutch Monographs on ancient history and archaeology), 1993, p. 13-30.

45. Voir respectivement ici : le compte rendu par H. Diels de F. G. Kenyon, Aristotle, On the Constitution of Athens, Londres, British Museum - Longmans and Co, 1891, in Deutsche Literaturzeitung, 12, 1891, p. 240; U. von Wilamowitz-Moellendorff, Aristoteles und Athen, Berlin, Weidmannsche Buchhandlung, 1893, p. 346 sq. ; Jacoby 1949, et Chambers 1993, 44 en particulier; B. Niese, «Ueber Aristoteles Geschichte der athenischen Verfassung ", Historische Zeitschrift, 69, 1892, p. 38-68 [38 sq.] ; F. Cauer, Hat Aristoteles die Schrift vom Staate der Athener geschrieben? Ihr Ursprung und ihr Werth für die ältere athenische Geschichte, Stuttgart, Göschen, 1891, p. 76-78. 
contraire, une neutralité politique ou un désir d'objectivité 46 ? Cherche-t-il encore à fusionner des traditions politiques différentes ${ }^{47}$ pour livrer un point de vue personnel sur l'histoire athénienne?

De la vivacité des controverses et de l'incapacité des historiens contemporains à trouver une solution consensuelle, il faut sans doute conclure au défaut du questionnement posé. La solution du débat historiographique n'est peut-être pas tant à trouver dans le texte d'Aristote que dans notre représentation de l'intellectuel des mondes anciens. Plutôt que d'envisager la Constitution d'Athènes dans une perspective politique anachronique et la tradition associant Pisistrate à l'âge de Cronos comme une donnée au service d'une étude historique, il est sans doute plus prudent de les considérer d'abord pour ce qu'elles sont fondamentalement : des arguments mis au service du projet philosophique aristotélicien.

\section{Pisistrate au temps de Cronos, une tradition au cœur des polémiques intellectuelles du IV ${ }^{\mathrm{e}}$ siècle}

Acceptons dès lors d'éclairer la tradition célébrant Pisistrate sous un jour nouveau et de voir en lui le fruit de l'historia aristotélicienne.

Produit de la nature, animal politique, Pisistrate est susceptible, comme tout être vivant, d'être l'objet d'une enquête empirique ${ }^{48}$. Plus ramassé que son précédent hérodotéen, le portrait aristotélicien du tyran tend, comme les analyses biologiques du Stagirite, moins à l'encyclopédisme qu'à la démonstration théorique ${ }^{49}$. Pas plus qu'il ne faut dénombrer de façon exhaustive tous les animaux pour les classer en grandes familles, il n'est question, dans la Constitution d'Athènes, de conter dans le détail les vicissitudes du parcours de Pisistrate. Sans céder entièrement à une vision téléologique de l'histoire, Aristote entend probablement composer un dossier sur Pisistrate utile pour comparer les tyrannies grecques ${ }^{50}$ entre elles et ainsi servir ses théories politiques.

46. Cf. J. de Romilly 1991.

47. Cf. Mathieu 1915, V-VI.

48. Sur l'influence des recherches biologiques sur le vocabulaire et la pensée politiques d'Aristote, cf. Day \& Chambers 1962, 38 sq. Sur le rapport chez Aristote entre l'enquête (historia) et l'expérience (empeiria), voir Premiers Analytiques, I, 30, 46 a 4-27, et Darbo-Peschanski 2007, 112-118.

49. Sur l'absence de prétention encyclopédique de la zoologie aristotélicienne, voir Crubellier \& Pellegrin 2002, 286. Sur la visée théorique des traités aristotéliciens de sciences naturelles, cf. ibid., 265 sq.

50. Aristote, Politique, IV , 4, 1290 b 25 sq., rappelle combien la méthode comparative des constitutions politiques est similaire à celle utilisée pour classer les animaux. Voir aussi Weil 1960, $317 \mathrm{sq}$. 
Menée à partir des investigations des disciples du Lycée ${ }^{51}$, l'enquête sur Pisistrate suit également la voie méthodologique empirique ouverte par les traités aristotéliciens de sciences naturelles. Elle se fie ainsi surtout aux sens pour sélectionner des informations : il faut relever des indices ${ }^{52}$, repérer les traces visibles du legs pisistratique ${ }^{53}$ et écouter les traditions orales. Réhabilitée par Isocrate ${ }^{54}$, régulièrement mise à profit par Aristote, la consultation des traditions orales comme celle affirmant que «la tyrannie de Pisistrate était la vie du temps de Cronos» est considérée comme une étape sur le chemin menant à la vérité. Les rumeurs, les légendes, les proverbes, les maximes ont eux aussi leur intérêt, car ils expriment la pensée de la majoritée ${ }^{55}$.

Comme les autres traités aristotéliciens ${ }^{56}$ qui commencent par une doxographie dont la légitimité repose sur la conviction que les opinions des autres portent une part de vérité ${ }^{57}$, il s'agit, avec le portrait de Pisistrate, de repérer tous les endoxa ${ }^{58}$, qu'ils appartiennent au commun - les on-dit ${ }^{59}$ - comme au plus savant, de les hiérarchiser en fonction de leur audience ${ }^{60}$, de leur vraisemblance ${ }^{61}$, et non de leur

51. Cf. Jaeger 1997, 341; I. Düring, Aristoteles, Darstellung und Interpretation seines Denkens, Heidelberg, Universitätsverlag Winter (Bibliothek der klassischen Altertumswissenchaften, N.F., 2. Reihe; 114) $1966\left(2005^{2}\right)$, p. 524 sq. ; Lynch 1972, 87.

52. Cf. Aristote, Constitution d'Athènes, XIII, 5 (sèmeion).

53. Il en va ainsi du nom du «champ non imposable» (cf. Aristote, Constitution d'Athènes, XVI, 6).

54. Cf. Larran 2011, 216-219.

55. Cf. Aristote, Rhétorique, II, 21, 1395 a.

56. Par exemple Aristote, Éthique à Nicomaque, I, 4, 2-4; De l'âme, II, 1, 403 b; Politique, I, 3, 1253 b 15-21; I, 13,1260 b 20-24.

57. Cf. S. Mansion, «Le rôle de l'exposé critique des philosophies antérieures chez Aristote», in Aristote et les problèmes de méthode, S. Mansion (dir.), Louvain-la-Neuve, Publications universitaires (Aristote. Traductions et Études), 1961, p. 35-56, et Crubellier \& Pellegrin 2002, 27.

58. Pour Aristote, Topiques, I, 1, $100 \mathrm{~b}$ 21, un endoxon est une opinion (doxa) admise "par tout le monde, ou par la majorité des gens, ou par les plus réputés et ceux qui ont les opinions les plus valables». Darbo-Peschanski 2007, 126 sq., traduit endoxa par «opinions communes »; Crubellier \& Pellegrin 2002, 112 et 134 sq., par «opinions valables».

59. Pour Aristote, les hommes du commun comme les philosophes peuvent avoir part à la vérité (cf. Crubellier \& Pellegrin 2002, 393).

60. Pour Crubellier \& Pellegrin 2002, 134 sq., «Il est important de remarquer que cette liste des opinions qui comptent comme opinions valables a un ordre qui va du plus au moins. Une opinion qui reçoit l'agrément de tout le monde est plus valable que celles qui reçoivent celui d'une majorité de gens ou des sages. Ces dernières ne comptent comme opinions valables qu'en l'absence d'opinion valable de rang supérieur». La Constitution d'Athènes accorde ainsi un grand crédit aux on-dit colportés par tous (cf. XVI, 7), retient les opinions partagées par tous les savants (cf. V, 3), se range souvent à l'avis de la majorité (cf. VI, 4; XII, 1) et accorde enfin une attention particulière aux historiens les plus réputés, tels Hérodote et Thucydide.

61. La Constitution d'Athènes cherche à suivre les interprétations historiques les plus vraisemblables (cf., par exemple, VI, 2-4, et IX, 2). 
orientation politique, de les critiquer ${ }^{62}$, de les épurer ${ }^{63}$, de les compiler ${ }^{64}$ et de les fusionner ${ }^{65}$ pour espérer avancer sur le chemin de la connaissance,

car celui qui est apte à trouver les endoxa est dans la même disposition que celui qui est apte à trouver la vérité.

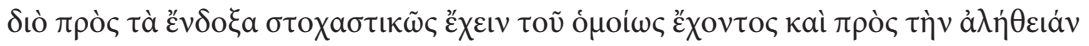
$\dot{\varepsilon} \sigma \tau \nu^{66}$.

Écouter les traditions orales populaires et d'une façon générale les différents endoxa sur le sujet traité relève ainsi chez Aristote d'une démarche méthodologique propre aux œuvres ésotériques ${ }^{67}$, parmi lesquelles il faut ranger la Constitution d'Athènes. Texte conçu pour l'usage interne du Lycée, rédigé sans souci littéraire, composé d'une série de notes destinées à être retravaillées à plusieurs reprises et à plusieurs mains ${ }^{68}$, le portait de Pisistrate ne souffre pas ainsi de ses contradictions. Il en vit. Parce que l'élaboration de la connaissance aristotélicienne est le fruit de discussion collective, de jugement, d'arbitrage et de lente maturation intellectuelle ${ }^{69}$, il faut, dans le cadre d'une recherche ouverte, mettre sans cesse les endoxa à la question pour en retenir les meilleurs, indépendamment les uns des autres, sans chercher à les fondre préalablement dans une argumentation cohérente. Dans un siècle ouvert par les leçons de Socrate, la vérité ne s'impose pas d'elle-même,

62. Au sujet du portrait de Pisistrate dans la Constitution d'Athènes, Rhodes 1981, 180, 185 et 189, note qu'Aristote donne, contre le récit d'Hérodote, une dimension politique à la faction de Pisistrate, modifie son nom (Diakrioi contre Hyperakrioi : cf. Constitution d'Athènes, XIII, 4 / Hérodote, I, 59, 3) et puise dans les Atthis des détails chronologiques en conflit avec l'Enquête. Aristote, Constitution d'Athènes, XVI, 4; XVIII, 2 et 4, prend également le contre-pied de Thucydide au sujet de l'impôt prélevé par le tyran, du nombre de conjurés contre les Pisistratides et du désarmement des Athéniens par Hippias (cf., respectivement, Thucydide, VI, 54, 5; VI, 56, 3; VI, 56, 2)

63. Pour la ruse du char de Pisistrate, Aristote, Constitution d'Athènes, XIV, 4, présente ainsi une version moins poétique que celle d'Hérodote, I, 60 (cf. Larran 2011, 205 sq.).

64. Pour Aristote, Métaphysiques, II, 1, 993 a 30-b 5, le progrès de la connaissance scientifique résulte d'un processus cumulatif de contributions individuelles. La Constitution d'Athènes compile ainsi la version d'Hérodote et celle de l'Atthis pour livrer l'histoire la plus complète de la tyrannie de Pisistrate (cf. Rhodes 1981, 191; 203; 205).

65. Pour Mathieu 1915, 50 sq., Aristote fusionne ainsi des versions contradictoires dans son récit des dénonciations d'Aristogiton (cf. Constitution d'Athènes, XVIII, 4 sq.).

66. Aristote, Rhétorique, I, 1, 1355 a 16 sq. Voir aussi Aristote, Métaphysiques, II, 993 a 30-b 5.

67. Les œuvres d'Aristote se composent de deux sortes de traités : les traités exotériques, produits pour être publiés et qui sont aujourd'hui tous perdus; les traités ésotériques, destinés à l'usage interne du Lycée.

68. Cf. Crubellier \& Pellegrin 2002, 29-35.

69. Voir ici Hadot 1995, 139-141, et Darbo-Peschanski 2007, 125-132. Ober 1998, 353-358, considère ainsi qu'Aristote joue, dans la Constitution d'Athènes, le rôle d'arbitre et de modérateur entre les différentes interprétations partisanes de l'histoire athénienne. 
évidente ou inspirée par les dieux, elle est parole partagée, conclusion consensuelle et vraisemblable, affaire de débat et de discussion. Les contradictions de la figure de Pisistrate ne sont pas ainsi les stigmates d'une pensée prise en défaut, mais bien la marque du procès de production du savoir aristotélicien.

Passée au crible de la méthode d'investigation du Stagirite, la tradition orale du chapitre XVI de la Constitution d'Athènes célèbre un tyran qui puise ses qualités dans le panthéon des vertus de l'éthique aristotélicienne : doux (praos), humain (philanthrôpos), indulgent (suggnômonikos), modéré (mètrios), juste, généreux, proche du peuple (dèmotikon $)^{70}$... Le tableau héraldique des qualités de Pisistrate reprend presque terme pour terme les vertus retenues dans la Rhétorique:

Les parties de la vertu sont la justice, le courage, la tempérance, la munificence, la magnanimité, la libéralité, la douceur, la sagesse pratique, la sagesse spéculative. Les plus importantes sont nécessairement les plus utiles à autrui, puisque la vertu est la faculté d'être bienfaisant.

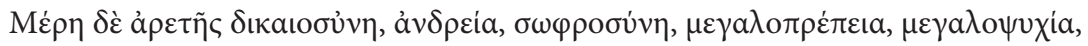

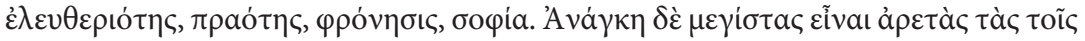

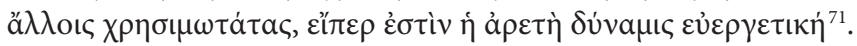

Pour aspirer au titre de bon dirigeant aristotélicien, il manque cependant encore à Pisistrate la prudence. Si la Constitution d'Athènes ne mentionne pas explicitement cette qualité, force est cependant de reconnaître que l'ensemble des vertus que le traité prête au tyran suggère qu'il appartient à la même espèce d'administrateurs que Périclès ${ }^{72}$. La formule "la tyrannie de Pisistrate était la vie du temps de Cronos» confirme d'ailleurs qu'il assure, comme les hommes politiques les plus prudents ${ }^{73}$, le bonheur des siens.

Le portrait est flatteur, la sélection des informations orientée, l'intention délibérée. Porté par une légende dorée célébrant les vertus de sa tyrannie, Pisistrate s'offre à Aristote comme un exemple type de ses théories politiques. Loin de nos canons contemporains de l'analyse, il s'agit moins de brosser un portrait historiquement juste que d'élaborer une figure philosophiquement utile. Sa fonction est sans doute triple.

70. Pour l'ensemble de ces qualités, voir Aristote, Constitution d'Athènes, XVI, 2-8. Sur l'importance nouvelle de la douceur et de l'indulgence dans l'éthique d'Aristote, voir J. de Romilly 1979, 194 sq.

71. Aristote, Rhétorique, I, 9, 1366 b 1-5 (traduction Dufour 1932, 108). Voir aussi Aristote, Éthique à Nicomaque, III-VI, VIII-IX.

72. Cf. Aristote, Éthique à Nicomaque, VI, 5, 5. L'échec des Pisistratides confirme par ailleurs l'hypothèse d'Aristote, Éthique à Nicomaque, X, 9, 18, selon laquelle la prudence n'est pas une qualité transmissible aux descendants. Voir aussi Aubenque 1963, 58.

73. Cf. Aristote, Éthique à Nicomaque, VI, 12, 1; VI, 12, 6. 
Elle rappelle tout d'abord à des contemporains, bercés par les bruits élogieux sur le tyran athénien, que le bonheur d'une communauté civique repose d'abord sur des qualités humaines, telles que la douceur, l'humanité et la justice ${ }^{74}$, toutes nécessaires pour renforcer la philia entre ses membres ${ }^{75}$. Par sa capacité à agir en citoyen (politikôs) et non en tyran despotique, Pisistrate «ne gênait en rien le peuple et veillait à sa tranquillité ${ }^{76}$. Il montre alors l'exemple à suivre ${ }^{77}$ et ouvre ainsi, comme le rappelle la tradition orale étudiée, la voie aux Athéniens du VI siècle vers l'idéal de la cité aristotélicienne, le bien vivre (to eu zèn $)^{78}$.

La figure de Pisistrate s'offre également aux élèves du Lycée comme une démonstration concrète des théories politiques aristotéliciennes. Si l'exemple de ses prises de pouvoir ${ }^{79}$ valide l'idée selon laquelle les changements de politeia s'effectuent tantôt par la ruse tantôt par la violence ${ }^{80}$, les traditions orales retenues au chapitre XVI de la Constitution d'Athènes illustrent, en consacrant le succès de la politique menée par Pisistrate, le bien-fondé des conseils suggérés aux tyrans dans le livre $\mathrm{V}$ de la Politique. Aristote remarque ainsi :

Un moyen de maintenir la tyrannie, c'est de rendre son autorité plus royale [...]. Tout d'abord, [le tyran] doit paraître se soucier des fonds publics, ne les gaspillant pas en cadeaux qui irritent les masses populaires, quand on arrache à leur travail et à leur peine, sordidement, un argent que l'on prodigue sans compter à des courtisanes, à des étrangers et à des artistes [...]. Le tyran prendra un air, non pas sévère, mais grave, et, en outre, propre à inspirer à ceux qui le rencontrent, non pas la peur, mais plutôt le respect [...]. Il ne doit donner prise, ni lui-même ni aucune personne de son entourage, au moindre soupçon d'outrage envers l'un de ses sujets, jeune homme ou jeune fille [...]. Et comme les États se composent de deux groupes, les gens pauvres et les riches, ce qui importe avant tout pour les uns et les autres, c'est qu'ils comprennent que leur salut dépend du pouvoir [...]. [...] [le tyran doit montrer] aussi [que], dans toute sa vie, il recherche la mesure et non l'excès; [...].

74. Cf. Aristote, Éthique à Nicomaque, V, 1, 8; V, 1, 13 .

75. Cf. Aristote, Éthique à Nicomaque, VIII, 1, 3-4, et J. de Romilly 1979, 190.

76. Cf., respectivement, Aristote, Constitution d'Athènes, XVI, 2 ; Politique, VII, 2, 1324 a 37-38; Constitution d'Athènes, XVI, 7.

77. Pour Aristote, Politique, VII, 13, 1332 a 31-33, une cité est vertueuse quand ses dirigeants le sont. Aristote, Éthique à Nicomaque, I, 13, 2, pense que «l'homme véritablement apte à diriger la cité consacre, plus que quiconque, ses efforts à faire régner la vertu. Il désire en effet faire des hommes de bons citoyens, dociles aux lois» (traduction Voilquin 1950, 45).

78. Pour Aristote, la fin de la politique est le bonheur de la communauté civique (to eu zèn) (cf. Politique, I, 2, 1252 b 27-30; III, 10, 1281 a 34-35), lequel passe par l'existence vertueuse de ses membres (cf. Politique, III, 9, 128 o b 5-9; VII, 8, 1328 a 36-43).

79. Cf. Aristote, Constitution d'Athènes, XIV-XV.

80. Cf. Aristote, Politique, V, 4, 1304 b 7-17, et Contogiorgis 1978, 227-230. 


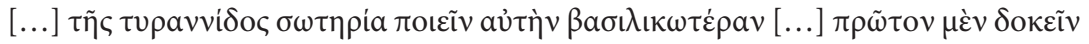

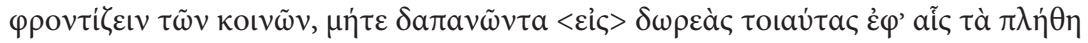

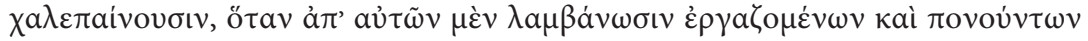

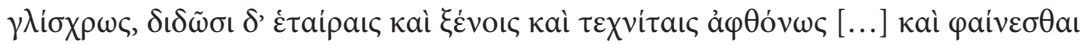

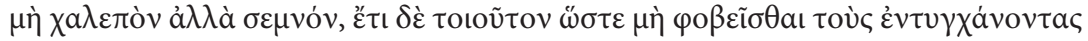

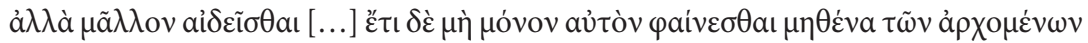

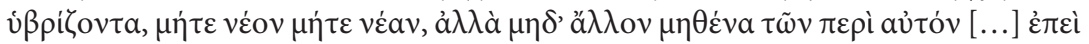

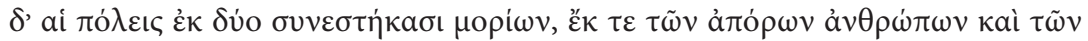

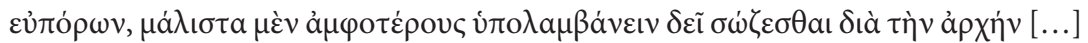

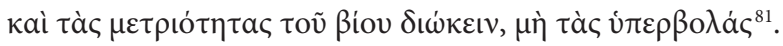

Longtemps considérés comme un machiavélisme avant la lettre, les conseils d'Aristote ont surtout comme objectif de tempérer les dérives tyranniques ${ }^{82}$ des dirigeants de son temps et ainsi de les empêcher de saper la communauté civique en ses fondements ${ }^{83}$. En jouant au roi ${ }^{84}$ vertueux, respectueux des lois et bienveillant à l'égard de son peuple, le tyran Pisistrate est là comme preuve de la possibilité de redresser la pire des constitutions déviées ${ }^{85}$. Pacificateur, il sait mener une politique à même de faire taire les différends entre le peuple et les notables et de réconcilier ainsi les deux groupes habituellement en lutte dans les cités :

[...] son pouvoir dura longtemps et, chaque fois qu'il était chassé, il le reprenait facilement. Car la plupart des nobles et des gens du peuple y consentaient : il attirait les uns par ses propos, les autres par ses secours pour leurs affaires privées, et il était par nature bien disposé envers les deux clans.

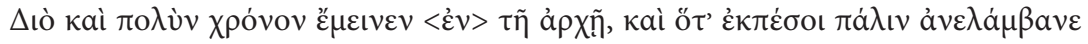

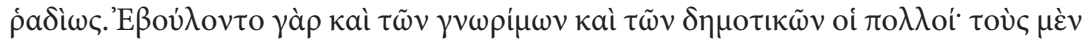

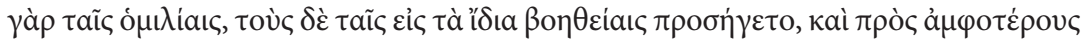

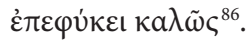

Stabilisateur, il se maintient longtemps au pouvoir ${ }^{87}$ et évite ainsi le retour d'une stasis qui déchirait Athènes avant l'établissement de sa tyrannie. Il honore, de cette façon, l'objectif proposé à tout législateur de garantir durablement le respect

81. Aristote, Politique, V, 11, 1314 a 34-1315 b 3 (traduction Aubonnet 1973, 87-9o).

82. Voir Vergnières 1995, 244 sq.

83. D'après Aristote, Politique, V, 11, 1314 a 15-29, le tyran cherche à réduire la cohésion sociale (philia) de sa cité et à détourner ses sujets de la sphère politique en avilissant leur âme et en leur retirant tout pouvoir d'agir. Voir ici Contogiorgis 1978, 132-136, et Petit 1993, 84 sq. notamment.

84. Sur la volonté de Pisistrate de mimer la royauté, voir éventuellement Larran 2011, 227-234.

85. Cf. Aristote, Politique, IV, 2, 1289 a 37-b 4; V, 10, 1310 b 1-7; voir aussi Petit 1993, 73.

86. Aristote, Constitution d'Athènes, XVI, 9 (traduction Sève 2006, 85).

87. Cf. Aristote, Constitution d'Athènes, XVI, 9; XVII, 1, et Politique, V, 12, 1315 b 11-39. 
des lois ${ }^{88}$ et, gage de sa qualité ${ }^{89}$, la survie du régime politique ${ }^{90}$. Souple et modéré comme les meilleurs dirigeants ${ }^{91}$, Pisistrate assure le bonheur des Athéniens en respectant les bonnes lois de Solon ${ }^{92}$ comme la justice de l'Aréopage ${ }^{93}$ et tend ainsi, en entrelaçant autorité monarchique et législation démocratique ${ }^{94}$, à construire un régime politique mixte qui a les faveurs d'Aristote ${ }^{95}$.

Les traditions sur Pisistrate mentionnées dans la Constitution d'Athènes pourraient bien également servir la vocation polémique des conceptions politiques aristotéliciennes ${ }^{96}$. Spectatrice d'un mouvement de recrudescence des régimes tyranniques ${ }^{97}$, de l'affirmation de la monarchie macédonienne comme, d'une façon plus générale, de l'individu d'exception, la littérature savante du IV ${ }^{\mathrm{e}}$ siècle cristallise son attention sur la figure du monarque idéal ${ }^{98}$ et se divise sur la nature de ses qualités. Platon, Xénophon, Isocrate, Aristote..., chacun apporte sa contribution au débat et livre une œuvre qui, bien souvent, cherche à répondre à celle de ses prédécesseurs ${ }^{99}$. Indifférente à l'utilisation qu'en feront les philosophes et les historiens contemporains, la pensée aristotélicienne entend elle aussi participer, armée de son réalisme

88. Cf. Aristote, Politique, II, 9, 1269 a 14-29.

89. Cf. Vergnières 1995, 236; 244.

90. Cf. Aristote, Politique, VI, 5, 1319 b 33-41.

91. Alors qu'en matière éthique, l'éloge d'Aristote va à celui qui est prompt à adopter le juste milieu en évitant l'excès et le défaut (cf. Éthique à Nicomaque, VI, 1, 1), dans le domaine politique, il revient aux dirigeants modérés capables, tel Solon, de mener une politique du juste milieu (cf. Constitution d'Athènes, V, 1-3; VI, 2-4; XII, 2) ou susceptibles, tel Théramène, d'agir en citoyen modèle en soutenant toutes les formes de gouvernement qui respectent les lois (cf. Constitution d'Athènes, XXVIII, 5).

92. Cf. Aristote, Constitution d'Athènes, XI, 2. - Aristote, Rhétorique, II, 23, 1398 b, rappelle clairement que les Athéniens qui ont suivi les lois de Solon ont connu une existence heureuse.

93. Cf. Aristote, Constitution d'Athènes, XVI, 8.

94. Sur les continuités entre la démocratie solonienne et le régime de Pisistrate, cf. Day \& Chambers $1962,67 s q . ; 92$.

95. En faveur auprès d'Aristote, le régime de Solon mêle ainsi savamment des caractéristiques démocratiques, oligarchiques et aristocratiques (cf. Aristote, Politique, II, 1273 b 35-1274 a 17). La politie est, quant à elle, un heureux mélange d'institutions démocratiques et oligarchiques (cf. ibid., IV, 8-9, 1293 b 22-1294 b 41; et Moraux 1964, 143 sq. notamment).

96. Sur le caractère polémique de la littérature politique athénienne du IVe siècle, cf. Carlier 1995, 255.

97. Cf. Mossé 1963, 164 sq.

98. Platon (La République, Le Politique), Xénophon (La Cyropédie, Agésilas) et Isocrate (À Nicoclès, Évagoras) se penchent ainsi sur la question de la supériorité du pouvoir monarchique. Sur l'affirmation possible d'un courant idéologique monarchiste au IV ${ }^{\mathrm{e}}$ siècle, voir Carlier 1995, 254 sq., et Mossé 2001, 156 sq. ; 164.

99. D'après Aulu-Gelle, Nuits attiques, 14, 3, 3, et Diogène Laërce, III, 34, Xénophon aurait ainsi composé la Cyropédie pour répondre au système de gouvernement proposé par Platon dans la République. 
empirique ${ }^{100}$, à l'agôn intellectuel qui confronte les écoles de pensée athéniennes ${ }^{101}$. Structurée en fonction des questionnements majeurs de son époque, la figure de Pisistrate permet au Stagirite de prolonger ${ }^{102}$ ou bien de répondre, point par point, aux analyses de ses devanciers.

S'agit-il d'en découdre au sujet de la nature du régime tyrannique? Contre le radicalisme des théories platoniciennes et la rigidité de son système de succession des politeiai, le bon gouvernement de Pisistrate célébré dans la Constitution d'Athènes est là pour rappeler que la tyrannie peut adopter des traits monarchiques ${ }^{103}$ et qu'elle est susceptible de naître, non pas de la démocratie extrême ${ }^{104}$, mais d'un régime modéré ${ }^{105}$. Contre la lecture isocratique du passé athénien ${ }^{106}$, la complexité du régime tyrannique du $\mathrm{VI}^{\mathrm{e}}$ siècle ne constitue pas, aux yeux d'Aristote, une parenthèse dans l'histoire de la démocratie athénienne ${ }^{107}$, mais un régime établi dans la continuité de l'entreprise législative solonienne ${ }^{108}$.

100. Sur le réalisme aristotélicien, son opposition à l'idéalisme platonicien et sur sa remise en cause actuelle, voir Châtelet 1974, 180-183; Contogiorgis 1978, 160; Louis 1990, 53; Crubellier \& Pellegrin 2002, 152 sq.

101. Sur l'opposition entre le Lycée d'Aristote et l'Académie de Platon, cf. Diogène Laërce, V, 2, et Crubellier \& Pellegrin 2002, 20-22; 24; 46. Sur la rivalité entre Aristote et Isocrate, voir Isocrate, Lettre à Alexandre (cf. Mathieu 1925, 185); Denys d'Halicarnasse, Isocrate, 18; Diogène Laërce, V, 11.

102. Le portrait aristotélicien de Pisistrate emprunte ainsi des traits au topos de la figure tyrannique classique. Comme chez Platon (cf. République, I, 344 a; Lois, X, 908 d) et Xénophon (cf. Mémorables, III, 9, 10), le tyran dépeint par Aristote accède au pouvoir par la ruse. Comme chez Platon (cf. République, VIII, 566 d-e; IX, 577 a-b), il s'y maintient par son jeu d'acteur (chez Xénophon, Cyropédie, VIII, 1, 40, Cyrus assure également qu'il est nécessaire de jouer la comédie devant le peuple). Comme Platon, République, VIII, 565 d, Aristote, Politique, V, 10, 1310 b 8-31, constate que le tyran agit en démagogue. Comme la plupart des théoriciens du IV ${ }^{e}$ siècle influencés par le portrait du tyran du livre VIII de la République de Platon, Aristote reproche à la tyrannie, d'une façon générale, son caractère arbitraire et despotique (cf. Politique, III, 8, 1279 b 17-18; et Mossé 1963, 169).

103. Inscrite dans le prolongement des conseils de modération donnés par Xénophon au tyran dans Hiéron, la position d'Aristote s'oppose ici, par sa souplesse et par son attention à la complexité historique, aux remarques de Platon, Lettres, VIII, 354 a-c, selon lesquelles le tyran doit nécessairement se convertir en roi pour aspirer au rang de bon dirigeant.

104. Cf. Platon, République, VIII, 562 a.

105. Cf. Aristote, Politique, V, 12, 1316 a 1 sq; 1316 a 35 sq.

106. Cf. Aréopagitique (VII), 15-16; Panathénaïque (XII), 148.

107. Cf. Constitution d'Athènes, XVI, 6; XVI, 8. Sur la tradition représentant Pisistrate comme partisan de la démocratie, voir Calabro 1984.

108. Même si Aristote, Constitution d'Athènes, XIV, 1, et XLI, 2, voit dans le régime institué par Pisistrate la quatrième rupture (metabolè) de l'histoire athénienne, il rappelle qu'il se distingue par son respect du peuple et des lois de Solon (cf. Constitution d'Athènes, XVI; Day \& Chambers 1962, $67 s q . ; 92 s q$.$) .$ 
Faut-il s'affronter sur les qualités de l'homme tyrannique? La tradition associant la tyrannie de Pisistrate au temps de Cronos invite à nuancer l'opposition établie au $I^{e}$ siècle entre le bon roi et le mauvais tyran dominé par la satisfaction insatiable de ses intérêts personnels ${ }^{109}$. Chez Aristote, le tyran Pisistrate brille par les qualités prêtées au bon dirigeant par Platon ${ }^{110}$, Xénophon ${ }^{111}$ et Isocrate ${ }^{112}$. Prudent et sage, il tire profit d'un habile mélange des diverses sortes de régimes politiques ${ }^{113}$ et obtient l'obéissance librement consentie ${ }^{114}$ d'un peuple ignorant les dangers de l'oisiveté. Aristote rappelle à ce sujet :

Pisistrate $[\ldots]$ avançait de l'argent aux indigents pour leurs activités, en sorte qu'ils tirent leur subsistance de l'agriculture. Il faisait cela pour deux raisons : afin qu'ils ne passent pas leur temps en ville, mais soient dispersés dans la campagne, et afin qu'ils aient une aisance suffisante et vaquent à leurs affaires sans désirer s'occuper des affaires publiques ni en avoir le loisir.

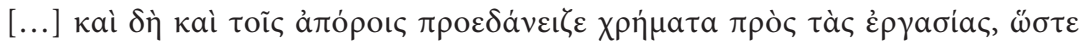

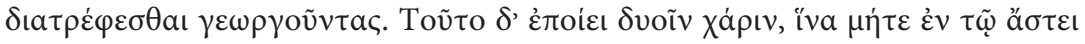

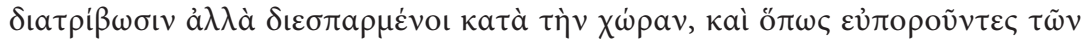

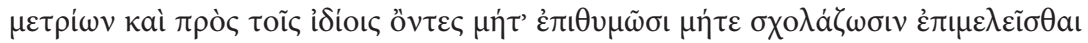
$\tau \tilde{\omega} \nu \operatorname{\kappa olv} \tilde{\omega} v^{115}$.

109. Voir Platon, Politique, 276 e; 301 a-c; Xénophon, Mémorables, IV, 6, 12 ; Aristote, Politique, III, 14, 1285 a 24-29; IV, 1295 a 17 sq. ; V, 10, 1311 a 2 sq. ; Rhétorique, I, 8, 1365 b 37 sq. ; Éthique à Nicomaque, VIII, 10, 2. Sur les notions de basileus et tyrannos chez Platon, voir M. Piérart, «Les figures du roi et du tyran dans les Lois de Platon », Ktèma, 16, 1991, p. 219-227; chez Isocrate : J.-P. Liou, «Isocrate et le vocabulaire du pouvoir personnel : roi, monarque et tyran ", ibid., p. 211-217.

110. Pour Platon, République, IV, 427 c- 435 d, la cité parfaite compte quatre vertus cardinales : la sagesse, le courage, la tempérance et la justice.

111. Cyrus: Anabase, I, 9, 16 (justice); I, 9, 22 (générosité) - Jason de Phères: Helléniques, VI, 1, 16 (tempérance) - Agésilas : Agésilas, III, (humanité et loyauté); IV (désintéressement); V (tempérance, justice); VI (courage); VII (respect des lois).

112. Démonicos : À Démonicos (I), 15, 20, 21 (modération, maitrise de soi, douceur, justice) - Évagoras : Évagoras (IX), 23 (courage); 43 (humanité); 44 sq. (modération, maîtrise de soi, bienfaisance); 49 (douceur); 65 (prudence) - Nicoclès : À Nicoclès (II), 16; 20 ; 23 (justice); 26 et 29-32 (tempérance, maîtrise de soi, justice); 15-16 et 23-24 (douceur).

113. Pisistrate agit ainsi de la même façon qu'Évagoras (cf. Isocrate, Évagoras [IX], 46).

114. L'obéissance consentie est généralement tenue comme la marque des bons dirigeants (cf. Xénophon, Économique, IV, 19; Cyropédie, I, 1, 3; I, 6, 21; III, 1, 28, etc.).

115. Aristote, Constitution d'Athènes, XVI, 2-3 (traduction Sève 2006, 84); cf. aussi Constitution d'Athènes, XVI, 5. - Sur les prêts accordés par Pisistrate aux petits paysans pour résoudre la crise agraire athénienne, voir notamment L.-M. L'Homme-Wéry, «La législation de Solon : une solution à la crise agraire d'Athènes?», Pallas, 64, 2004, p. 144-155. 
En refusant l'oisiveté à ses sujets, Pisistrate agit finalement comme Cyrus ${ }^{116}$ ou comme le bon tyran chez Isocrate ${ }^{117}$ et permet à la cité athénienne de connaître une tranquillité civique ${ }^{118}$ célébrée par des traditions populaires.

Dans une perspective comparable, Aristote prend clairement parti dans le débat sur l'origine des vertus politiques du dirigeant idéal. Encore une fois, il s'agit de battre en brèche la pensée platonicienne et de s'écarter des conceptions politiques de Xénophon et d'Isocrate. Que faut-il au dirigeant? Une solide éducation philosophique? de savants conseils? Contre le roi philosophe platonicien ${ }^{119}$, à la différence des dirigeants brillamment guidés chez Xénophon et Isocrate ${ }^{120}$, le Pisistrate d'Aristote montre que l'expérience et la prudence sont deux vertus politiques suffisantes pour mener une cité mais difficiles à transmettre durablement aux descendants du chef ${ }^{121}$.

Est-il enfin nécessaire de poursuivre le débat classique sur le bonheur politique $^{122}$ ? Le réalisme pragmatique d'Aristote prend une fois de plus le contre-pied des conceptions idéalistes. Les conceptions platoniciennes et aristotéliciennes de l'âge de Cronos s'opposent ainsi nettement. Dans Les Lois, Platon explique notamment :

Car les cités dont nous avons plus haut exposé la formation ont été encore précédées, et de fort loin, par le règne et le peuplement si prospères que la légende place au temps de Cronos et dont il y a un reflet dans les meilleures de nos organisations actuelles [...]. Cronos, dit-on, savait, comme nous l'avons exposé, qu'aucun homme ne peut, de par sa nature, régler en maître absolu toutes les affaires humaines sans se gonfler de démesure et d'injustice; et dans cette pensée il imagina de préposer alors à nos cités, pour rois et pour chefs, non pas des hommes mais des êtres d'une race supérieure et plus divine, des démons [...]. [...] et eux [...] ils prirent soin de nous, et par la paix, le sens de l'honneur, la bonne législation et l'abondance de justice

116. Cf. Xénophon, Cyropédie, I, 6, 17-18.

117. Cf. Isocrate, Lettre à Timothée, 3.

118. Cf. Aristote, Constitution d'Athènes, XVI, 7 ; Isocrate, Aréopagitique (VII), 51 sq. Sur l'interprétation de l'idéal de la tranquillité civique au IVe siècle, voir Demont 1990, 47-51.

119. Cf. Platon, Lettres, VII, 326 a-b; République, V, 463 a sq., 473 d; Politique, 293 d-e, 297 a-b; Lois, III, 688 e, 69 o b-c.

120. Pour Xénophon, Mémorables, III, 9, et IV, 2, l'art du commandement s'acquiert par l'expérience et par le conseil. Chez Isocrate, le bon souverain doit tirer son savoir politique de l'expérience, des conseils comme des spéculations théoriques (cf. À Nicoclès [II], 4; 10-13; 35).

121. Si Hippias semble avoir hérité des vertus de son père, on notera que la tyrannie se durcit après l'assassinat d'Hipparque et précipite ainsi sa fin (cf. Aristote, Constitution d'Athènes, XVI, 7 ; XVIII-XIX). Sur la question de la transmission héréditaire du pouvoir politique chez Aristote : cf. Politique, III, 15, 1286 b 22-27; V, 10, 1312 b 18-33.

122. Pour une idée partielle des principaux enjeux de ce débat, cf. Xénophon, Cyropédie, VIII, 1, 1; VIII, 1, 44; Agésilas, VII; Hiéron, XI; Platon, République; Lois; Lettres, VII, 327 d; Isocrate, Nicoclès (III), 31-32; Évagoras (IX), 43 et 49; Aristote, Rhétorique, II, 23, 1298 b. Voir aussi Châtelet 1974, 161. 
qu'ils nous procuraient, préservèrent des révolutions et établirent dans le bonheur l'espèce humaine. Or ce discours prétend, maintenant encore, et en cela il dit vrai, que dans les cités où règne non un dieu mais un mortel, les citoyens ne peuvent se soustraire aux maux et aux peines; nous devons au contraire, pense-t-il, imiter par tous les moyens la vie légendaire du temps de Cronos et obéir à tout ce qu'il y a en nous de principes immortels pour y conformer notre vie publique et privée, administrer d'après eux nos maisons et nos cités, donnant à cette dispensation de la raison le nom de loi.

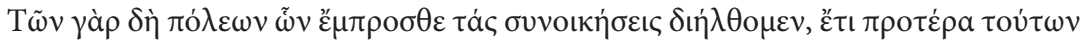

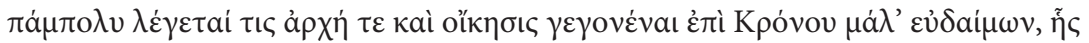

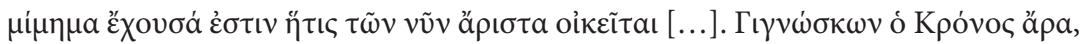

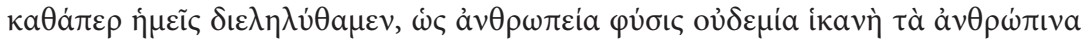

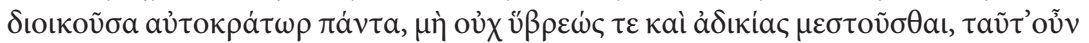

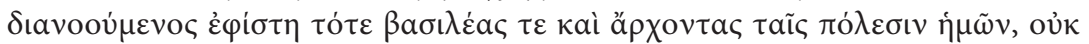

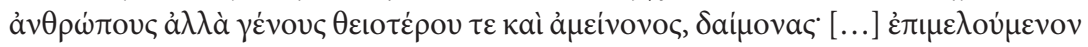

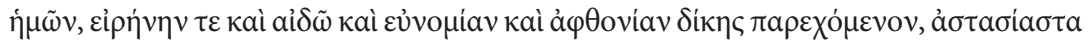

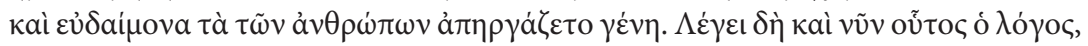

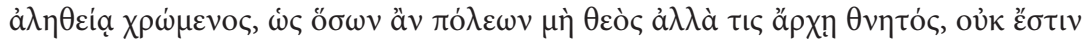

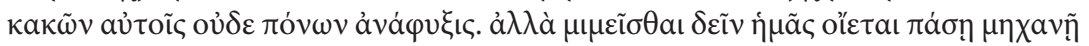

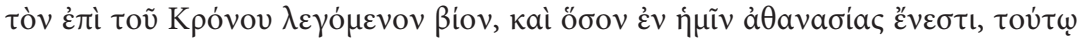

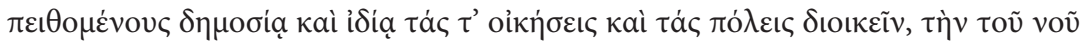

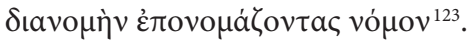

Contre l'idée platonicienne selon laquelle les communautés humaines ayant vécu à l'âge de Cronos appartiennent à un inaccessible passé idéal dirigé par des puissances divines (daimones), Aristote préfère suivre la voie isocratique de l'éloge d'un épisode historique athénien, celui de la patrios politeia ${ }^{124}$, associer l'âge d'or à la tyrannie de Pisistrate et rappeler ainsi qu'une communauté politique heureuse appartient au domaine du possible ${ }^{125}$ et du praticable ${ }^{126}$.

Le bruit «la tyrannie de Pisistrate était la vie du temps de Cronos» sert manifestement les prises de position d'Aristote dans le débat intellectuel du IV siècle sur la figure à donner au dirigeant idéal. Prompt à contrarier ses prédécesseurs,

123. Platon, Lois, IV, 713 b-714 a (traduction des Places 1951, 61 sq.). Voir encore Platon, Politique, 271 d-272 c, 275 b-c. À la différence du Critias, 109 b-e, Platon renonce ici à présenter comme contemporains l'ordre non politique de Cronos et l'ordre politique du gouvernement de Zeus.

124. Pour Isocrate, Aréopagitique (VII), 15-16; 58-59, l'idéal est le retour à la constitution des ancêtres.

125. Voir Châtelet 1974, 167; Weil 1964, 180-182.

126. Aristote, Politique, VII, 2, 1325 a 7-10, fixe ainsi les devoirs du législateur : «Et l'office du sage législateur est de considérer, pour un État, une famille de peuples ou toute autre communauté, comment sera réalisée leur participation à une vie bonne, et au bonheur qu'il est leur possible d'atteindre» (traduction Tricot 1962, 477); voir encore Politique, VI, I, 3, 1288 b 37. 
probablement sensible à l'idée de conseiller ${ }^{127}$ le dirigeant politique ${ }^{128}$, Aristote assigne un objectif clair à l'enquête sur les 158 politeiai grecques à la fin de l'Éthique à Nicomaque :

Tout d'abord, efforçons-nous de compléter tout ce qu'ont dit d'une manière satisfaisante, quoique fragmentaire, nos devanciers; ensuite nous rassemblerons les différentes constitutions; puis nous envisagerons les conditions favorables ou défavorables aux États en général et aux formes particulières de gouvernement, ainsi que les raisons qui font, ou non, la bonne administration des États. Ces considérations nous permettront de mieux discerner le meilleur gouvernement, les institutions, les lois et les mœurs qui lui assurent cette supériorité.

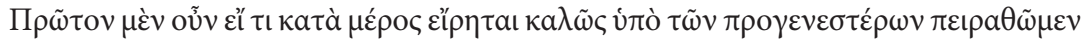

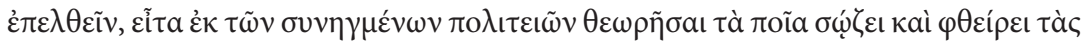

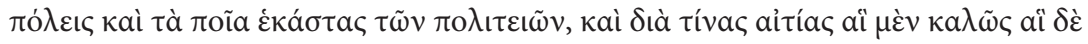

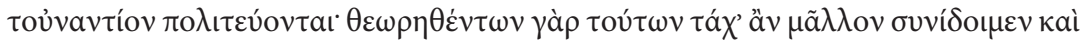

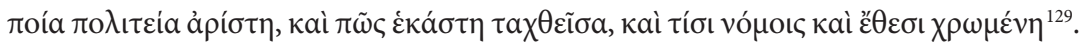

C'est ainsi par la mise en parallèle d'exemples historiques ${ }^{130}$, de régimes politiques et de dirigeants ${ }^{131}$ qu'Aristote peut envisager de sortir l'histoire du contingent ${ }^{132}$ et du particulier ${ }^{133}$ pour la faire accéder au général ${ }^{134}$ et à l'utilité philosophique. La démarche semble nécessaire, car elle conditionne l'appréhension des phénomènes

127. Les conseils donnés par Aristote au livre V de la Politique en vue de modérer la politique des tyrans de son temps s'inscrivent ainsi dans le prolongement de ceux prodigués par Platon à Denys l'Ancien (cf. Lettres, VIII, 354 a) ou bien encore par Xénophon (cf. Hiéron, IX-XI) et par Isocrate (cf. Hélène [X], 32 sq.).

128. Déjà lors de son séjour à Atarnée, il cherche sans doute à influencer le tyran Hermias, qu'il croit acquis aux idées de la philosophie : cf. Diogène Läerce, V, 3, 9, 10; Jaeger 1997, 112-117; Louis 1990, 50-53. Avec Diogène Laërce, V, 4, et Louis 1990, 80, on retiendra que des éléments légendaires assurent qu'Aristote a donné des lois à la cité de Stagire une fois refondée.

129. Aristote, Éthique à Nicomaque, X, 9, 23 (traduction Voilquin 1950, 509).

130. Sur le rôle de l'exemple historique dans l'élaboration des théories politiques d'Aristote, voir notamment Gregorio 2001, 79 sq.

131. Les comparaisons historiques menées dans la Politique permettent notamment d'approfondir la connaissance des dirigeants tyranniques : cf. Politique, V, 10, 1310 b 8-31.

132. Sur l'histoire comme règne de la contingence chez Aristote, cf. Poétique, XXIII, 1459 a 17 sq.; Châtelet 1974, 194 sq.; 205; Vergnières 1995, 229 sq.

133. En réaction probable aux histoires banales et annalistiques de l'Atthis, Aristote, Poétique, IX, 1451 a 36-b 1, rappelle que la poésie a un caractère plus philosophique et plus intéressant que l'histoire, car la première traite du général, la seconde du particulier. Sur la célèbre opposition entre histoire et poésie chez Aristote, voir par exemple Gregorio 2001, 72; Hartog 2005, 41.

134. Cf. Weil 1964, 162 sq.; Vergnières 1995, 230; Darbo-Peschanski 2007, 130-132. 
politiques et permet de tirer des enseignements à même d'éclairer la délibération du législateur ${ }^{135}$ et d'orienter le travail de l'homme d'État ${ }^{136}$.

\section{Pisistrate au temps de Cronos, une invitation à l'action politique?}

Après Socrate et Alcibiade, Platon et Denys l'Ancien, Isocrate et Philippe de Macédoine, faut-il associer Aristote à Alexandre le Grand dans la prestigieuse liste des philosophes éducateurs des hommes politiques et voir alors dans le portrait de Pisistrate un miroir princier et dans les traditions célébrant les vertus de son gouvernement des invitations à l'action politique? La tentation de considérer le plus docte des philosophes comme l'inspirateur du plus grand ${ }^{137}$ des conquérants est forte ${ }^{138}$, mais sans doute dangereuse, car elle porte en elle le risque de la réécriture magnifiée. Contre le désir de placer les grands hommes aux commandes d'une glorieuse histoire ancienne, un examen détaillé des sources s'avère nécessaire pour séparer le bon grain historique de l'ivraie anachronique.

L'hypothèse selon laquelle Alexandre le Grand peut être considéré comme le destinataire du portrait de Pisistrate en général, et du bruit associant sa tyrannie à l'âge de Cronos en particulier, s'appuie sur deux arguments. Le premier relève de la conception aristotélicienne de l'histoire. Comme Isocrate ${ }^{139}$, le Stagirite considère le passé comme une source d'exemples utiles pour guider le présent ${ }^{140}$. L'histoire autorise notamment la mise en parallèle de dirigeants ${ }^{141}$, confrontés, tels Philippe

135. Cf. Aristote, Rhétorique, I, 8, 1365 b : «Ce qu'il y a de plus important et de plus efficace pour pouvoir persuader et bien conseiller est de connaitre toutes les constitutions, d'en distinguer les habitudes, les institutions et les intérêts" (traduction Dufour 1932, 106). Voir encore Rhétorique, I, 4, 1360 a 20-23; 30-36; Politique, II, 1, 126o b 27-35; IV, 1, 1288 b 22-33 et 1289 a 11-23.

136. Une connaissance approfondie des différentes constitutions est ainsi indispensable au dirigeant politique pour connaître la constitution la mieux adaptée au réel et déterminer la marche à suivre pour redresser une constitution déviée (cf. Aristote, Politique, IV, 1, 1288 b 21-1289 a 10; IV, 14, 1297 b 37-38).

137. Tel est en tout cas l'avis de Plutarque (notamment Vie d'Alexandre, 7, 2).

138. Sur l'ambition prêtée à Aristote de faire d'Alexandre un philosophe roi, cf. Louis 1990, 64 .

139. Cf. Aréopagitique (VII), 78 sq.; N. Loraux, L'invention d'Athènes. Histoire de l'oraison funèbre dans la "cité classique», Paris, Éditions de l'EHESS - La Haye, New York, Mouton (Civilisations et Sociétés; 65), 1981, p. 120; F. Hartog, L'histoire, d'Homère à Augustin. Préfaces des historiens et textes sur l'histoire, Paris, Seuil (Points essais; 388), 1999, p. 103 sq.

140. Cf. Rhétorique, I, 9, 1368 a, et II, 20, 1394 a. Au IV siècle, la représentation du passé comme source d'exemples pour guider le présent est largement partagée : cf. Démosthène, Sur la couronne, 95 et 210; Lycurgue, Contre Léocrate, 100; Hartog 2005, 34; 43; 67-68.

141. Aristote, Politique, V, 11, 1313 b 21-25, compare ainsi la politique tyrannique des pharaons et celle des Pisistratides, car elles consistent toutes deux à appauvrir, par le biais de constructions monumentales, leurs sujets. 
de Macédoine et les Pisistratides ${ }^{142}$, à des problèmes politiques de même nature. De sa capacité à se reproduire d'un siècle à l'autre comme d'un monde à l'autre, le passé athénien offre à Alexandre la possibilité de guider son action. À lui dès lors d'écouter les traditions célébrant la geste pisistratique et de voir dans le tyran athénien l'étalon modérateur de sa conduite volontiers intempérante.

Fondée en théorie, l'hypothèse est encore affermie par les faits. Aristote a bien été le maître d'Alexandre. Lié à la cour macédonienne par son père Nicomaque, qui fut le médecin du roi Amyntas, le Stagirite assura, encouragé par Philippe, la formation littéraire, scientifique et politique du jeune Alexandre ${ }^{143}$. Ces quelques années d'enseignement furent-elles cependant assez longues pour assurer une influence durable de la philosophie aristotélicienne sur le Conquérant? Elles n'y auraient sans doute pas suffi sans le concours d'intermédiaires, qui ont maintenu Alexandre, tout au long de son règne, en contact avec la pensée d'Aristote. Les sources mentionnent trois noms. D'abord Nicanor, parent du Stagirite et courtisan suffisamment influent pour être placé à la tête de l'ambassade envoyée en 324 à Olympie afin d'annoncer aux Grecs l'exigence d'Alexandre de recevoir des honneurs divins ${ }^{144}$. Ensuite Antipater, proche d'Aristote et représentant tout puissant d'Alexandre en Grèce et en Macédoine ${ }^{145}$. Enfin Callisthène, neveu et disciple d'Aristote, historien officiel d'Alexandre, chargé de coucher par écrit sa geste glorieuse et ainsi préparer les Grecs à voir en lui un héros surhumain ${ }^{146}$.

Confortée par l'accumulation d'indices, l'envie est toujours plus forte de voir en Aristote le maître à penser d'Alexandre et de considérer le portrait aristotélicien de Pisistrate comme un miroir princier. Ami des lettres, de la philosophie et des sciences naturelles ${ }^{147}$, Alexandre aurait même affirmé, selon Plutarque, que

il n'aimait [Aristote] pas moins que son père, parce que, si l'un lui avait donné la vie, l'autre lui avait appris à bien vivre.

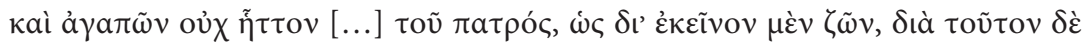
$\kappa a \lambda \tilde{\omega} \varsigma \zeta \tilde{\omega} \nu^{148}$.

142. Aristote, Politique, V, 10, 1311 a 28-b 6, rappelle ainsi que l'outrage déclenche la révolte de Pausanias contre Philippe comme celle d'Harmodios et d'Aristogiton contre les Pisistratides.

143. Voir ici Diogène Laërce, V, 1; V, 4; Plutarque, Vie d'Alexandre, 7, 1-5; Louis 1990, 61; 65-67. Selon Dascalakis 1965, 175 notamment, et Louis 1990, 68, le traité d'Aristote Sur la royauté - dont il ne reste presque rien - aurait été destiné à l'éducation du prince Alexandre.

144. Cf. Jaeger 1997, 331.

145. Cf. Jaeger 1997, 122, et Louis 1990, 95 sq.

146. Voir notamment Goukowsky 1978, 22 sq.; 25; Pédech 1984, 15 sq., et Mossé 2001, 78.

147. Cf. Plutarque, Vie d'Alexandre, 7 sq.; 10 sq.

148. Plutarque, Vie d'Alexandre, 8, 4 (traduction Flacelière \& Chambry 1975, 38 sq.). Voir aussi Sur la fortune d'Alexandre, I, 4 (Moralia, 327 F). 
Qui croit-on cependant entendre ici? Alexandre, admirateur d'Aristote? Plutarque, maître ouvrier de la légende dorée du Conquérant? La seconde solution risque, décevante, de s'imposer.

Projection anachronique incapable de plonger ses racines dans les strates les plus anciennes de la tradition, l'amitié entre Aristote et Alexandre n'a ni la grandeur ni la force que le moraliste souhaite lui prêter. Si Aristote a bien été le maître d'Alexandre, il est nécessaire de rappeler qu'il fut sans doute un second choix pour Philippe et qu'il n'était pas encore à cette époque le grand fondateur du Lycée ${ }^{149}$. Si Aristote est resté en contact avec Alexandre, force est de constater que leurs relations se sont distendues ${ }^{150}$. Contre les intentions présumées d'Aristote de le convertir en dirigeant modéré et respectueux des lois ${ }^{151}$, les tentations absolutistes d'Alexandre, sa divinisation et son projet de fusion entre les Gréco-Macédoniens et les peuples sous domination perse prouvent que le Conquérant s'est comporté en disciple plutôt rétif.

La mise à distance critique de la tradition légendaire d'Alexandre interdit-elle pour autant de considérer le portrait aristotélicien de Pisistrate comme un miroir princier et la tradition célébrant son bon gouvernement comme une invitation stimulante à la modération politique? Si Alexandre n'a probablement pas consulté la Constitution d'Athènes, qui est avant tout un outil de travail du Lycée, il n'est pas complètement exclu que Callisthène, neveu d'Aristote et historien officiel du Conquérant ${ }^{152}$, s'en soit inspiré pour vanter, à la cour macédonienne, les vertus de modération du tyran athénien. Tout au long de l'expédition asiatique, Callisthène choisit de lutter pied à pied contre les justifications de l'absolutisme royal avancées par son rival Anaxarque ${ }^{153}$ :

149. Cf. Crubellier \& Pellegrin 2002, 15.

150. Cf. Louis 1990, 69. Les échanges épistolaires qu'on a pu leur prêter sont probablement apocryphes (pour le débat historiographique sur l'authenticité de la correspondance entre Aristote et Alexandre, voir notamment P. Carlier, «Étude sur la prétendue lettre d'Aristote à Alexandre», Ktèma, 5, 1980, p. 277-288, et R. Weil, «Sur la Lettre d'Aristote à Alexandre», in Aristoteles Werk und Wirkung. Mélanges P. Moraux, I, Aristoteles und seine Schule, J. Wiesner (éd.), Berlin - New York, de Gruyter, 1985, p. 485-498).

151. Pour Goukowsky 1978, 51-56, la Lettre d'Aristote à Alexandre sur la politique envers les cités (Texte arabe établi et traduit par J. Bielawski, commentaires de M. Plezia, Wroclaw - Varsovie - Cracovie, [Archivum Filologiczne; XXIV], 1970) doit être considérée comme un authentique programme de gouvernement assorti de conseils relatifs à l'art de bien gouverner et d'une mise en garde contre l'influence nocive de certains flatteurs (Anaxarque). Alexandre doit ainsi préférer la gloire du législateur à celle du soldat (Préambule, $1,1-4)$ et s'astreindre à respecter la justice pour éviter de se comporter en un tyran détesté $(7,5$ et 9-10; 12, 1-9).

152. Voir ici Pédech 1984, 15 sq.

153. Sur la rivalité entre Callisthène et Anaxarque, voir Plutarque, Vie d'Alexandre, 52, 8-9; Arrien, Anabase, IV, 10, 1, et Goukowsky 1978, 267. 
le meurtre de Cleitos n'est pas exploité politiquement ${ }^{154}$, la proskynèse est refusée ${ }^{155}$ et le tyrannicide évoqué devant des pages révoltés ${ }^{156}$. Est-il possible qu'en cette occasion, Callisthène ait fait l'éloge des tyrannicides Harmodios et Aristogiton pour mieux légitimer la contestation des dérives tyranniques d'Alexandre ${ }^{157}$ ? Une certitude demeure : Callisthène paiera de sa vie la conception aristotélicienne du bon dirigeant.

Quelle que soit sa pertinence, l'hypothèse suivant laquelle Callisthène aurait utilisé la figure de Pisistrate présente dans la Constitution d'Athènes pour orienter l'action d'Alexandre manque de preuve concrète. La prudence impose plutôt d'opter pour l'évidence en considérant les membres du Lycée comme ses principaux destinataires. Prise dans un débat politique ${ }^{158}$ qui divise la cité entre les partisans d'une indépendance acquise dans la douleur contre la Macédoine et ceux favorables à l'acceptation d'une tutelle tyrannique étrangère synonyme de servitude heureuse ${ }^{159}$, cette élite intellectuelle est sans doute plus à même qu'Alexandre d'entendre l'éloge aristotélicien d'un tyran qui aurait permis aux Athéniens de vivre comme au temps de Cronos.

Dans l'Athènes placée sous tutelle macédonienne, il est fréquent d'établir un parallèle entre la tyrannie de Pisistrate et la monarchie de Philippe et d'Alexandre le Grand. Habitués au Lycée à utiliser des exemples historiques comme clefs de lecture du présent, les disciples athéniens d'Aristote sont encore incités à se plonger dans l'histoire athénienne par Lycurgue, dont l'œuvre de régénération morale de la cité $^{160}$ passe par la redécouverte de son grandiose passé ${ }^{161}$. Les membres de l'école aristotélicienne sont régulièrement invités par les orateurs athéniens à voir dans les monarques macédoniens de terribles tyrans. Démosthène présente ainsi Philippe

154. Sur le meurtre de Cleitos et la différence de son exploitation politique par le modéré Callisthène et le partisan de l'absolutisme Anaxarque, voir Plutarque, Vie d'Alexandre, 50-52; Goukowsky 1978, 46.

155. Sur la rivalité de Callisthène et d'Anaxarque au sujet de la proskynèse et de son utilisation politique par Alexandre, cf. Arrien, Anabase, IV, 10, 5-12, 6, et Goukowsky 1978, 47-49.

156. Callisthène tenait des conférences devant de hauts dignitaires comme devant de jeunes pages, attirés par le franc-parler de l'historien ainsi que par son refus des dérives tyranniques d'Alexandre, que certains d'entre eux auraient même tenté d'assassiner. Callisthène, impliqué dans l'affaire, est alors exécuté (cf. Plutarque, Vie d'Alexandre, 55, 2-9; Arrien, Anabase, IV, 13 sq., et Goukowsky 1978, $49 ; 55)$.

157. Cf. Arrien, Anabase, IV, 10, 3-4, et Pédech 1984, 16 sq. Sur l'évocation du tyrannicide par Callisthène chez Plutarque, voir Vie d'Alexandre, 55, 2-4.

158. Sur la situation politique athénienne au temps d'Alexandre, voir Mossé 1963, 164 notamment.

159. Cf. Démosthène, Sur la couronne, 203-206.

160. Sur la politique de Lycurgue visant à redonner force, grandeur et indépendance à la cité athénienne après Chéronée, voir notamment Habicht 2000, 26 sq. ; 41-43; 47 sq. Aristote montre un intérêt manifeste pour la politique de renouveau athénien menée par Lycurgue, comme le suggère la minutieuse description de l'éphébie livrée au chapitre XLII de Constitution d'Athènes (cf. Habicht 2000, 43).

161. Cf. Contre Léocrate, 98. 
comme un tyran absolu qui, esclave de ses vices et gonflé d'hybris ${ }^{162}$, ignore la paix, la liberté et la justice ${ }^{163}$. Critiqué pour sa violence liberticide, considéré comme «le tyran de la Grèce ${ }^{164}$, Alexandre est encore associé aux Pisistratides ${ }^{165}$ par le Pseudo-Démosthène dans le discours Sur le traité avec Alexandre:

Supposons, Athéniens, que l'on vous demande quelle sorte de contrainte vous indignerait le plus, tous sans doute vous répondriez que, si les Pisistratides vivaient de notre temps et si quelqu'un prétendait les restaurer ici par la force, vous, plutôt que de les accueillir, vous saisiriez vos armes et vous affronteriez tous les dangers [...]. Eh bien, lorsque, contrairement aux serments et aux stipulations écrites du traité de paix, Alexandre restaure à Messène les fils de Philiadès, qui sont bien des tyrans, a-t-il souci de la justice? ou plutôt ne se conduit-il pas lui-même en tyran selon sa coutume, sans la moindre considération pour vous ni pour les engagements communs?

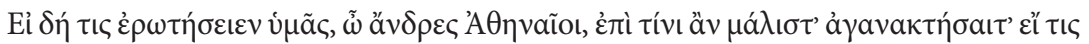

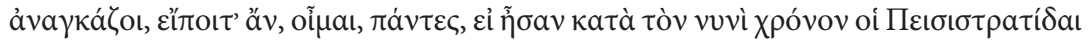

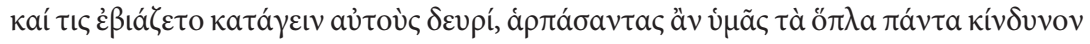

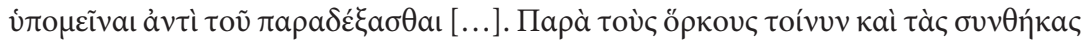

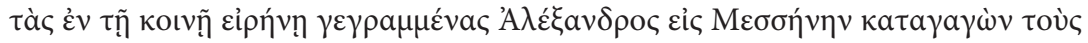

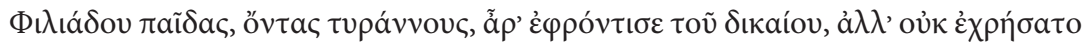

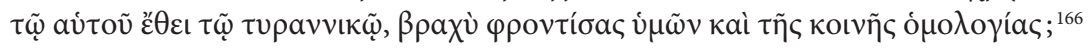

En dépit des efforts des partisans d'une négociation avec la Macédoine, la cité athénienne, pourtant défaite à Chéronée, se laisse régulièrement emporter par des accès d'ardeur patriotique ${ }^{167}$. À chaque fois, il s'agit de secouer le joug de la tyrannie macédonienne : en 335, Athènes envisage de soutenir la révolte thébaine contre la Macédoine; en 331, il faut encore irriter Olympias, la mère d'Alexandre, en parant à grands frais la statue de Dionè à Dodone; en 331, on entend soutenir la révolte du roi spartiate Agis; en 330, le procès de la Couronne sert de caisse de résonance à un patriotisme fervent, etc. ${ }^{168}$

162. Voir ici respectivement : Première Olynthienne, 3-4; Deuxième Olynthienne, 17-19; Première Philippique, 3, 37; Sur l'Halonnèse, 44; Troisième Philippique, 32.

163. Voir respectivement : Seconde philippique, 21; 24; 25, et Sur la couronne, 65-66; 72; Seconde Philippique, 7.

164. Cf. Pseudo-Démosthène, Sur le traité avec Alexandre, $4 ; 5 ; 6 ; 10 ; 12 ; 25 ; 29$.

165. D’une façon générale, le topos du mauvais tyran est régulièrement incarné, dans la seconde moitié du IV ${ }^{\mathrm{e}}$ siècle, par les Pisistratides. Tel est le cas chez les Athéniens comme chez les Macédoniens (cf. Démosthène, Lettre de Philippe, 6 sq.).

166. Pseudo-Démosthène, Sur le traité avec Alexandre, 3-4 (traduction de M. Croiset in Démosthène, Harangues II, Paris, Les Belles Lettres [CUF; 26], 1925, p. 165).

167. Cf. Habicht 2000, 45-48.

168. Pour une analyse de ces épisodes, voir Habicht 20oo, 34;39;40; 46. 
Soutenu et financé par la Macédoine ${ }^{169}$, proche d'Antipater ${ }^{170}$, hôte d'une cité qui doit se résigner à supporter l'autorité d'Alexandre, Aristote cherche peut-être lui aussi à utiliser la légende dorée de Pisistrate pour atténuer les tensions politiques et convaincre les Athéniens des bénéfices à tirer de la mise sous tutelle macédonienne ${ }^{171}$. Clef de lecture partisane du présent, le portrait élogieux de Pisistrate pourrait s'offrir comme un miroir où les Athéniens sont susceptibles de retrouver le fils de Philippe de Macédoine : Alexandre n'est-il pas, comme Pisistrate, un tyran qui joue au roi et qui accepte de conserver leur régime démocratique pour mieux assurer le bonheur de la cité athénienne? De cette mise en parallèle et des engagements politiques qu'elle laisse espérer, chacun peut tirer profit.

Du côté d'Aristote, l'acceptation par les Athéniens de la tutelle macédonienne est la garantie qu'il se maintiendra à la tête du Lycée et poursuivra son travail philosophique. Du côté d'Alexandre, le contrôle politique de la communauté athénienne est le gage qu'il pourra mener, serein, son expédition en Asie.

Du côté athénien, l'arrivée d'un nouveau Pisistrate a de quoi séduire. Athènes connaît-elle dans les années 320 une situation économique difficile ${ }^{172}$ ? À l'instar de Pisistrate, qui a permis à leurs ancêtres de vivre comme à l'âge de Cronos ${ }^{173}$, Alexandre propose aux Athéniens une paix souvent garante de prospérité. Athènes cherche-t-elle à soutenir les Grecs dans leur rébellion contre le pouvoir macédonien? Dans le prolongement de la politique de Pisistrate respectueuse de la législation solonienne, Alexandre choisit de maintenir le régime démocratique athénien et refuse d'intervenir dans les affaires intérieures de la cité ${ }^{174}$. Comme Pisistrate, qui assure paix et tranquillité à son peuple, Alexandre se distingue par une politique bienveillante à l'égard de ses sujets athéniens : plus doux que son père ${ }^{175}$, il accepte, après l'écrasement de la révolte thébaine, en 335, de ne pas exiger la tête des huit Athéniens les plus compromis; parti en guerre contre la Perse au nom de la défense

169. Cf. Athénée de Naucratis, IX, 398 e; Élien, Histoire variée, IV, 19; Pline l'Ancien, Histoire naturelle, 8, 44; Lynch 1972, 83, et Louis 1990, 89.

170. Cf. Diogène Laërce, V, 11, et Jaeger 1997, 323.

171. Cf. Jaeger 1997, 323. Les Athéniens considéraient Aristote comme un homme lié à la Macédoine, comme le suggèrent les railleries dont il l'accablèrent (cf., par exemple, Plutarque, De l'exil, 10, 604 d) et la violente réaction anti-macédonienne qui le frappa à la mort d'Alexandre le Grand (cf. Diogène Laërce, V, 5 sq. ; Élien, Histoire variée, III, 36 ; Jaeger 1997, 30 ; Louis 1990, 100 ; Crubellier \& Pellegrin 2002, 18 sq.).

172. Entre 331 et 324, Athènes est effectivement touchée par une durable pénurie de blé (cf. P. Garnsey, Famine and Food Supply in the Graeco-Roman World. Responses to Risk and Crisis, Cambridge, Cambridge University Press, 1988, p. 154-166, et Habicht 2000, 44 sq.).

173. Sur la prospérité économique athénienne au temps de Pisistrate, cf. Day \& Chambers 1962, 175.

174. Cf. Habicht 2000, 32.

175. D’après Levi 1978, Alexandre donne, à la différence de son père, l'impression de rechercher l'alliance des Grecs plutôt que leur soumission. 
de la liberté et de la lutte contre la tyrannie, il rétablit des démocraties en Asie, libère les Athéniens pris dans les rangs perses lors de la bataille du Granique, et envoie trois cents armures perses aux Athéniens pour venger les violences barbares perpétrées au temps des guerres médiques ${ }^{176}$... La politique bienveillante d'Alexandre à l'égard des Athéniens nourrira même la légende selon laquelle son expédition asiatique lui permit de rendre les statues des Tyrannoctones à leur cité d'origine ${ }^{177}$ !

Une fois de plus, les preuves explicites manquent. Aucun traité du Stagirite ne fait d'ailleurs la moindre allusion à l'actualité de son temps ${ }^{178}$. Il faut probablement reconnaître en cette absence la volonté d'Aristote de mener une observation suffisamment patiente et prudente pour éviter le piège d'un idéalisme trop directif, dont Platon fut victime ${ }^{179}$. À la conception platonicienne d'une philosophie entièrement impliquée dans la vie politique ${ }^{180}$ répond ainsi l'idéal théorétique aristotélicien, lequel, tourné vers la sagesse et le savoir, se borne seulement à former le jugement du législateur sans chercher à diriger son action et risquer ainsi de se laisser entraîner dans les turbulences de la vie politique ${ }^{181}$.

Ni véritablement historique, ni franchement politique, ni simplement philosophique, la figure aristotélicienne de Pisistrate semble se présenter, dans un siècle séduit par l'affirmation d'individus providentiels, comme un outil à penser. C'est bien à partir de figures individuelles, puisées dans les temps passés et relues à la lumière de préoccupations contemporaines ${ }^{182}$, que les penseurs athéniens proposent désormais de construire leurs analyses, de répondre à leurs devanciers et de guider leurs contemporains. Nourri de traditions populaires positives, le Pisistrate d'Aristote pourrait lui aussi tenir sa place parmi les personnages historiques revisités et instrumentalisés par Platon, Xénophon, Isocrate, les Atthidographes ou Aristote ${ }^{183}$.

176. Cf. Plutarque, Vie d'Alexandre, 16;17-18; 34, 1-2; Arrien, Anabase, I, 16, 6 sq. ; 29, 5; III, 6, 2. Voir aussi Goukowsky 1978, 19 sq.; 245; Habicht 2000, 34; 37, et Mossé 2001, 72.

177. Cf. Arrien, Anabase, III, 16, 7 sq., et Habicht 2000, 32.

178. Sur le silence d'Aristote au sujet de l'œuvre politique d'Alexandre, voir notamment Sinclair 1953, 222; Châtelet 1974, 199; Carlier 1995, 117.

179. Cf. Châtelet 1974, 203 sq.

180. Cf. Hadot 1995, 124.

181. Sur l'idéal théorétique et ses conséquences éthiques et politiques, voir Hadot 1995, 124-129; 142-144, et Crubellier \& Pellegrin 2002, 111 sq.; 187; 203-205.

182. Sur la construction des figures politiques par les hommes de savoir, voir R. Bodéüs, «Figures du politique», in Le savoir grec. Dictionnaire critique, J. Brunschwig, G. E. R. Lloyd et P. Pellegrin, Paris, Flammarion (Mille et une pages), 1996 (rééd. 2011), p. 198-222.

183. Sur l'utilisation des figures mythologiques et historiques comme exemples paradigmatiques au service des théories aristotéliciennes, voir notamment Aubenque 1963, 49 sq. 
Menée à partir d'investigations historiques, leur description s'offre surtout comme une clef de lecture partisane d'un passé appelé à orienter le présent de la cité. Au $I^{e}$ siècle, prendre parti pour Cyrus, tel Xénophon, ou pour Évagoras, tel Isocrate, conditionne non seulement la représentation du bon monarque, mais détermine aussi l'orientation des politiques à suivre pour mener correctement la cité ${ }^{184}$. Placer Thésée, Solon ou Clisthène à l'origine de la démocratie athénienne ne relève pas uniquement, dans les Atthis, d'une querelle d'historiens érudits, mais d'un débat engagé sur les choix politiques à prendre pour construire le régime athénien et guider son gouvernement ${ }^{185}$. Dans une perspective comparable, la reconstruction mythifiée d'un Lycurgue chez Platon ${ }^{186}$ comme celle d'un Solon chez Aristote ${ }^{187}$ ne signent pas leur incapacité à mener une enquête historique objective, mais offrent aux législateurs des sources d'inspiration. Replacée dans le contexte intellectuel $\mathrm{du} \mathrm{IV}^{\mathrm{e}}$ siècle, la reprise des traditions sur Pisistrate dans la Constitution d'Athènes pourrait elle aussi avoir comme vocation de soutenir les positions aristotéliciennes dans l'arène des rivalités de son temps.

Francis LARRAN

Lycée Martin Luther King, Bussy-Saint-Georges ArScAn (Maison René Ginouvès, Université de Paris Ouest Nanterre La Défense)

184. Cf. Isocrate, Évagoras (IX), 37-39.

185. Voir ici, par exemple, Jacoby 1949, 77.

186. Cf. Platon, Lettres, VIII, 354 a-c.

187. Cf. C. Mossé, «Comment s'élabore un mythe politique : Solon, "père fondateur" de la démocratie athénienne», Annales E.S.C., 34, 1979, p. 425-437. 


\section{Appendice - Le régime de Pisistrate d'après Aristote, Constitution d'Athènes, XVI, 2-9 (traduction Sève 2006, 83-85)}

2 [...] Pisistrate administrait avec modération les affaires de la cité, en citoyen plutôt qu'en tyran. Il était en général bienveillant et doux, et enclin au pardon envers les fautifs; et en particulier, il avançait de l'argent aux indigents pour leurs activités, en sorte qu'ils tirent leur subsistance de l'agriculture. 3 Il faisait cela pour deux raisons : afin qu'ils ne passent pas leur temps en ville, mais soient dispersés dans la campagne, et afin qu'ils aient une aisance suffisante et vaquent à leurs affaires sans désirer s'occuper des affaires publiques ni en avoir le loisir. 4 En même temps, il lui arriva que les ressources augmentèrent, puisque la campagne était cultivée : il percevait en effet la dîme des productions. 5 C'est pourquoi il créa les juges des dèmes, et lui-même sortait souvent dans la campagne pour inspecter et arbitrer les litiges, afin que les gens ne négligent pas leurs travaux en descendant en ville. 6 C'est au cours d'une de ces sorties, dit-on, qu'arriva à Pisistrate l'anecdote de l'homme qui cultivait sur l'Hymette le champ appelé plus tard le «champ non imposable». Avisant donc quelqu'un qui piochait et travaillait une terre qui n'était que pierres, par étonnement, il chargea son esclave de demander ce qui poussait dans le champ. "Rien que des maux et des douleurs», dit l'autre, «et il faut que Pisistrate prenne la dîme de ces maux et de ces douleurs». L'homme avait répondu sans le connaître, et Pisistrate, ravi de sa franchise et de son ardeur au travail, l'exempta de tout impôt. 7 Il ne gênait la foule en rien pendant sa domination, mais il préparait toujours la paix et maintenait la tranquillité. C’est pourquoi [lacune : on répétait souvent?] que la tyrannie de Pisistrate était la vie du temps de Cronos. En effet, il arriva plus tard que, ses fils lui ayant succédé, la domination devint beaucoup plus rude. 8 Mais le plus important de tout ce qu'on a dit est qu'il était d'un caractère affable et bienveillant. Car en tout domaine il voulait tout administrer conformément aux lois, sans s'attribuer aucun avantage. Un jour, cité à l'Aréopage pour une affaire de meurtre, il se présenta lui-même pour assurer sa défense, mais l'accusateur, pris de peur, fit défaut. 9 C'est pourquoi son pouvoir dura longtemps et, chaque fois qu'il était chassé, il le reprenait facilement. Car la plupart des nobles et des gens du peuple y consentaient : il attirait les uns par ses propos, les autres par ses secours pour leurs affaires privées, et il était par nature bien disposé envers les deux clans.

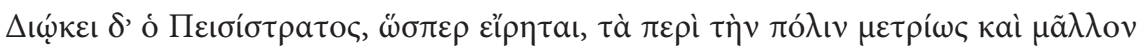

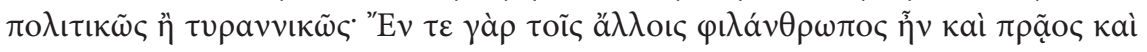

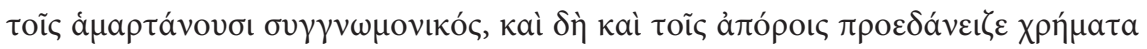

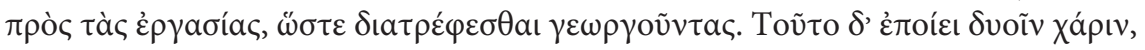

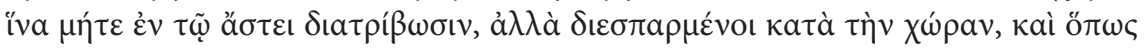

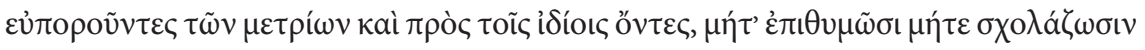




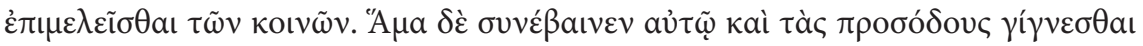

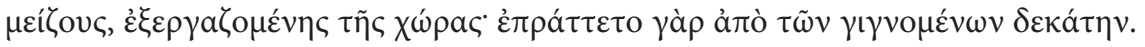

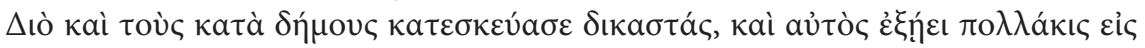

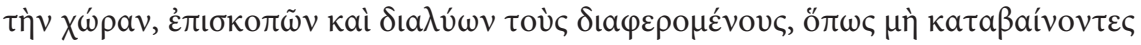

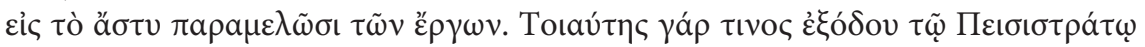

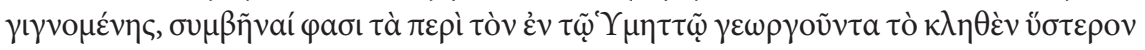

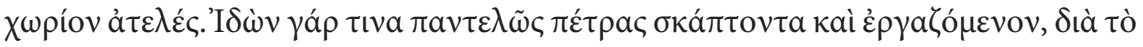

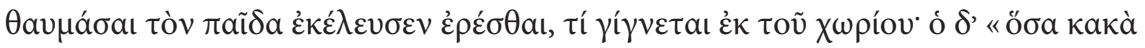

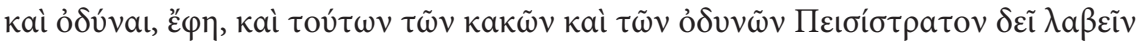

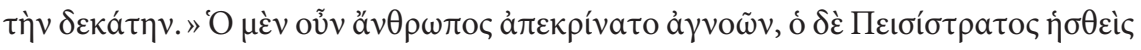

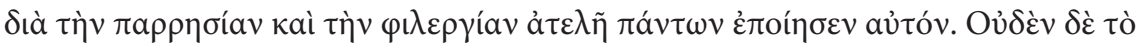

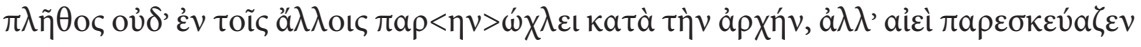

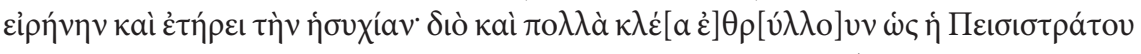

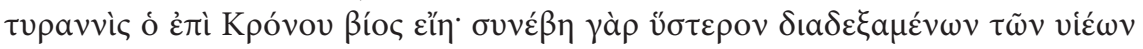

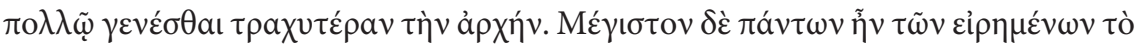

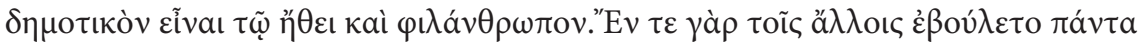

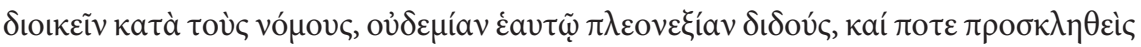

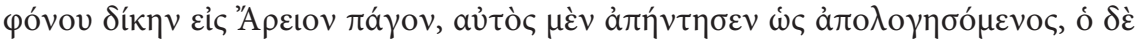

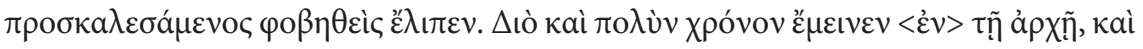

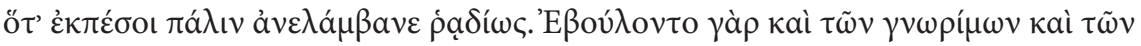

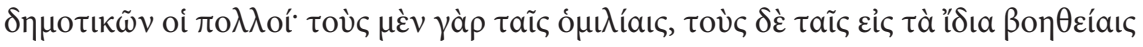

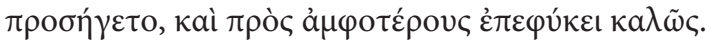

\section{Références bibliographiques}

\section{Auteurs anciens}

Aristote (Sève 2006), Constitution d'Athènes, Le régime politique des Athéniens, M. Sève (introd., trad. et notes), Paris, Librairie Générale Française (Le Livre de poche. Classique).

Aristote (Voilquin 1950), Éthique de Nicomaque [sic], J. Voilquin (éd., trad.), Paris, Garnier Frères (Classiques Garnier).

Aristote (Tricot 1962), La Politique, J. Tricot (éd.), J. Vrin (Bibliothèque des textes philosophiques).

Aristote (Aubonnet 1973), Politique. Tome II. Deuxième partie. Livres V-VI, J. Aubonnet (éd., trad.), Paris, Les Belles Lettres (CUF; 221). 
Aristote (Dufour 1932), Rhétorique. Tome I, Livre I, M. Dufour (éd., trad.), Paris, Les Belles Lettres (CUF; 68).

Aristote (Dufour 1938), Rhétorique. Tome II, Livre II, M. Dufour (éd., trad.), Paris, Les Belles Lettres (CUF; 90).

Hérodote-Thucydide (Barguet 1964), in Historiens grecs. I. Hérodote / Thucydide, J. de Romilly (introd.) - Hérodote : A. Barguet (prés., trad. et notes) - Thucydide : D. Roussel (prés., trad. et notes), Paris, Gallimard (Bibliothèque de la Pléiade; 176).

Platon (des Places 1951), Euvres complètes, Tome XI. Deuxième partie, Les Lois, Livres IIIVI, É. des Places (éd., trad.), Paris, Les Belles Lettres (CUF; 115).

Plutarque (Flacelière \& Chambry 1975), Vies, Tome IX, Alexandre - César, R. Flacelière, É. Chambry (éd., trad.), Paris, Les Belles Lettres (CUF; 237).

\section{Études}

Aubenque P. (1963), La prudence chez Aristote, Paris, PUF (Bibliothèque de philosophie contemporaine) (rééd. ibid. [Quadrige. Grands textes], 2009).

Aubenque P., Tordesillas A. (1993), Aristote politique. Études sur la "Politique» d'Aristote, Paris, PUF (Épiméthée).

BAldry H. C. (1952), «Who Invented the Golden Age?», CQ, 46, p. 83-92.

Bordes J. (1982), Politeia dans la pensée grecque jusqu'à Aristote, Paris, Les Belles Lettres (Études anciennes).

BRIsson L. (2009), «Le tyran dans les Lois : la violence fondatrice. Une lecture de Leg. IV 709 d-712 a», in Gastaldi \& Pradeau 2009, p. 129-155.

Cajani G., Lanza D. (2001), L'antico degli antici, Palerme, Palumbo (Letteratura classica; 23).

Calabro L. (1984), «Pisistrato in positivo. Un excursus sulla tradizione aneddotica pisistratea », Seia, I, p. 54-64.

CARlier P. (1995), Le IV siècle grec, jusqu'à la mort d'Alexandre, Paris, Seuil (Points. Série Histoire; 218 [Nouvelle histoire de l'Antiquité; 3]).

Chambers M. (1993), "Aristotle and his Use of Sources", in Aristote et Athènes, M. Piérart (dir.), Fribourg, Séminaire d'histoire ancienne de l'Université de Fribourg - Paris, de Boccard, p. 39-52.

Châtelet F. (1974), La naissance de l'histoire, Tome II, Paris, Union générale d'éditions (rééd. Seuil [Points essais; 323], 1996).

Christodoulou P. (2009), «Le tyran dans le rôle du roi. À propos du chapitre $11 \mathrm{du}$ livre V de la Politique d'Aristote», in Gastaldi \& Pradeau 2009, p. 157-177.

Contogiongis G. D. (1978), La théorie des révolutions chez Aristote, Paris, Librairie Générale de Droit et de Jurisprudence (Bibliothèque de philosophie du droit; 22). 
Crubellier M., Pellegrin P. (2002), Aristote. Le philosophe et les savoirs, Paris, Seuil (Points essais; 491).

DARbo-Peschanski C. (2001), «Se construire un devenir : enquête sur les catégories grecques de l'historicité», in Cajani \& Lanza 2001, p. 17-29.

Darbo-Peschanski C. (2007), L'Historia. Commencements grecs, Paris, Gallimard (Folio Essais; 497).

Dascalakis A. (1965), «La jeunesse d'Alexandre et l'enseignement d'Aristote», Studii Clasice, 7, p. 169-180.

Day J. H., Chambers M. (1962), Aristotle's History of Athenian Democracy, Berkeley Los Angeles, University of California Press (University of California. Publications in History; 73) (rééd. Amsterdam, A. M. Hakkert, 1967; Millwood [NY], Kraus Reprint, 1980).

Demont P. (1990), La cité grecque archaïque et classique et l'idéal de tranquillité, Paris, Les Belles Lettres (Études anciennes. Série grecque; 139).

Duff T. E. (2003), The Greek and Roman Historians, Londres, Bristol Classical Press Duckworth (Classical World Series).

Edmond M.-P. (200o), Aristote. La politique des citoyens et la contingence, Paris, Payot (Critique de la politique).

Gastaldi S. (2009), «La tirannide nella Politica di Aristotele», in Gastaldi \& Pradeau 2009, p. 139-155.

Gastaldi S., Pradeau J.-F. (2009), Le philosophe, le roi et le tyran. Études sur les figures royale et tyrannique dans la pensée grecque et sa postérité, Sankt Augustin, Academia Verlag (Collegium Politicum - Contributions to Classical Political Thought; 3 ).

GAuthier P. (1985), Les Cités grecques et leurs bienfaiteurs (IV ${ }^{e}-I^{e r}$ siècle av. J.-C.). Contribution à l'histoire des institutions, Athènes, École française d'Athènes - Paris, de Boccard (Bulletin de Correspondance Hellénique. Supplément; 12).

Goukowsky P. (1978), Essai sur les origines du mythe d'Alexandre (336-27o av. J.-C.), I, Les origines politiques, Nancy, Université de Nancy II (Annales de l'Est - Mémoire; 60).

Gregorio F. (2001), «Le rôle de l'histoire dans les Politiques d'Aristote ou la naissance de la philosophie politique», in Cajani \& Lanza, p. 71-82.

Навіснт С. (2000), Athènes hellénistique. Histoire de la cité d'Alexandre le Grand à Marc Antoine, Paris, Les Belles Lettres (Histoire; 43) (trad. par M. \& D. Knoepfler de Athen. Die Geschichte der Stadt in hellenistischer Zeit, Munich, C. H. Beck, 1995).

Надот P. (1995), Qu'est-ce que la philosophie antique?, Paris, Gallimard (Folio Essais; 280).

HARDING P. (1994), Androtion and the Atthis, the Fragments translated with Introduction and Commentary, Oxford, Oxford University Press (Clarendon Ancient History Series). 
Harding P. (2008), The Story of Athens. The Fragments of the Local Chronicles of Attika, Londres - New York, Routledge (Routledge Sourcebooks for the Ancient World).

Hartog F. (1997), "Le cas grec : du ktèma à l'exemplum en passant par l'Archéologie», Extrême-Orient, Extrême-Occident, 19, p. 127-137.

Hartog F. (2005), Évidence de l'histoire. Ce que voient les historiens, Paris, Éditions de l'EHESS (Cas de figure; 5) (rééd. Gallimard [Folio Histoire; 157], 2007).

Jacoвy F. (1949), Atthis. The Local Chronicles of Ancient Athens, Oxford, Clarendon Press (rééd. Oxford, Clarendon Press - New York, Arno Press, 1973).

Jaeger W. W. (1997), Aristote. Fondements pour une histoire de son évolution, Paris, Éditions de l'Éclat (Polemos) (= Aristoteles. Grundlegung einer Geschichte seiner Entwicklung, Berlin, Weidmann, 1923; Aristotle. Fundamental of the History of his Development, Oxford, Clarendon Press, 1934).

Kullmann W. (1993), «L'image de l'homme dans la pensée politique d'Aristote», in Aubenque \& Tordesillas 1993, p. 161-184.

LARRAN F. (2011), Le bruit qui vole. Histoire de la rumeur et de la renommée en Grèce ancienne, Toulouse, Presses universitaires du Mirail (Tempus; 49).

Levi M. A. (1978), «Filippo, Alessandro e l'opinione pubblica attica», CISA, 5, p. 59-67.

Louis P. (1990), Vie d'Aristote, Paris, Éditions Hermann (Savoir).

Lynch J. P. (1972), Aristotle's School, A Study of a Greek Educational Institution, Berkeley - Los Angeles - Londres, University of California Press.

Mathieu G. (1915), Aristote, Constitution d'Athènes. Essai sur la méthode suivie par Aristote dans la discussion des textes, Paris, É. Champion (Bibliothèque de l'École des hautes études, Sciences historiques et philologiques; 216).

Mathieu G. (1925), Les idées politiques d'Isocrate, Paris, Les Belles Lettres (rééd. ibid. [Études anciennes. Série grecque], 1966).

Momigliano A. (1983), Problèmes d'historiographie ancienne et moderne, Paris, Gallimard (Bibliothèque des Histoires).

Moraux P. (1964), «Quelques apories de la Politique et leur arrière-plan historique», in La «Politique» d'Aristote, Vandœuvres - Genève, Fondation Hardt (Entretiens sur l'Antiquité classique; XI), p. 127-148.

Moreau J. (1962), Aristote et son école, Paris, PUF (Les grands penseurs) (rééd. ibid. [Collection Dito] $\left.1985^{2} ; 1996^{3}\right)$.

Mossé C. (1963), «La tyrannie chez Aristote», in Geras, Studies presented to G. Thomson on the occasion of his 6oth birthday, L. Varcl, R. F. Willetts (éd.), Prague, Charles University (Graecolatina Pragensia; 2 - Acta Universitatis Carolinae, 1963. Philosophia et historica; 1), p. 163-169. 
Mossé C. (1969), La tyrannie dans la Grèce antique, Paris, PUF (Collection Hier) (rééd. ibid. [Quadrige. Grands textes], 2004).

Mossé C. (1996), "Introduction», in Aristote, Constitution d'Athènes, traduit par G. Mathieu et B. Haussoulier, revu par C. Mossé, Paris, Les Belles Lettres (Classiques en poche; 2 ).

Mossé C. (2001), Alexandre, la destinée d'un mythe, Paris, Payot (Biographie Payot).

Murray O. (1995), La Grèce à l'époque archaïque. Early Greece, Toulouse, Presses Universitaires du Mirail (amphi 7. Histoire) (rééd. ibid., 2011).

Ober J. (1998), Political Dissent in Democratic Athens. Intellectual critics of Popular Rule, Princeton (New Jersey) - Woodstock (Oxfordshire), Princeton University Press.

Pearson L. I. C. (1942), The Local Historians of Attica, Philadelphia, Lancaster Press - Oxford, Blackwell (Philological Monographs published by the American Philological Association; XI), 1942 (rééd. Londres, Greenwood Press, 1972; New York, Oxford University Press [American Philological Association. Philological Monographs; 11], 2000).

PÉDECH P. (1984), Historiens compagnons d'Alexandre, Callisthène, Onésicrite, Néarque, Ptolémée, Aristobule, Paris, Les Belles Lettres (Études anciennes) ( $2^{\mathrm{e}}$ tirage ibid. [Études anciennes. Série grecque; 99], 2011).

Pesely G. E. (1995), «Aristotle's source for the tyranny of Peisistratus », Athenaeum, 83, p. 45-66.

Petit A. (1993), «L'analyse aristotélicienne de la tyrannie», in Aubenque \& Tordesillas 1993, p. 73-92.

Petre Z. (200o), "Le temps des ruptures», in Constructions du temps dans le monde grec ancien, C. Darbo-Peschanski (éd.), Paris, CNRS Éditions (CNRS Philosophie), p. 357-370.

Rhodes P. J. (1981), A Commentary on the Aristotelian Athenaion Politeia, Oxford, Clarendon Press (rééd. New York, Oxford University Press Inc. [Clarendon Paperbacks], 1993).

Rhodes P. J. (1990), “The Atthidographers”, in Purposes of History, Studies in Greek Historiography from the 4 th to the and centuries B.C., H. Verdin, G. Schepens, E. de Keyser (éd.), Proceedings of the International Colloquium, Leuven, 24-26 may 1988, Louvain (Studia hellenistica; 30), p. 73-81.

Rhodes P. J. (1993), "Alles eitel gold” ? The Sixth and Fifth Centuries in Fourth-Century Athens", in Aristote et Athènes, Aristoteles und Athens (Séminaire d'histoire ancienne de l'Université de Fribourg, Fribourg, 23-25 mai 1991), études rassemblées par M. Piérart, Paris, de Boccard, p. 53-64. 
Romilly J. DE (1979), La douceur dans la pensée grecque, Paris, Les Belles Lettres (Études anciennes. Série grecque; 66) (rééd. ibid., 2011).

Romilly J. De (1980), Précis de littérature grecque, Paris, PUF (rééd. ibid. [Quadrige. Grands textes; 392], 2007).

Romilly J. De (1991), «Le fait politique», in Penser avec Aristote, M. A. Sinacoeur (dir.), Toulouse, Éditions Érès, p. 569-571.

Rosler A. (2005), Political Authority and Obligation in Aristotle, Oxford - New York, Oxford University Press (Oxford Aristotle Studies).

Sancisi-Weerdenburg H. (2000), Peisistratos and the Tyranny: a Reappraisal of the Evidence, Amsterdam, J. C. Gieben (Publications of the Netherlands Institute at Athens; 3).

Sinclair T. A. (1953), Histoire de la pensée politique grecque, Paris, Payot (Bibliothèque historique).

Van Effenterre H. (1967), L'histoire en Grèce, Paris, A. Colin (U2. Histoire ancienne; 13).

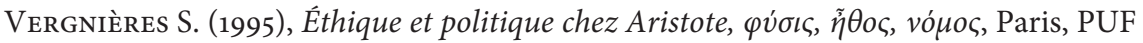
(Fondements de la politique. Série Essais).

Weil R. (1960), Aristote et l'histoire. Essai sur la "Politique", Paris, Librairie C. Klincksieck (Études et Commentaires; 36).

Weil R. (1964), «Philosophie et histoire. La vision de l'histoire chez Aristote», in La «Politique» d'Aristote, Vandœuvres - Genève, Fondation Hardt (Entretiens sur l'Antiquité classique; XI), p. 161-189.

Zatta C. (2010), «Making History Mythical: the Golden Age of Peisistratus », Arethusa, 43/1, p. 21-62. 
